\title{
Wetting and spreading behavior of Ti-based brazing filler on Ti64 substrate
}

\author{
Bolarinwa Komolafe ${ }^{1}$ and Ahmad Mostafa $* 1$ \\ ${ }^{1}$ Mechanical and Industrial Engineering Department, Concordia University, 1455 de \\ Maisonneuve Blvd. West, Montreal, Quebec, Canada, H3G 1M8
}

* Email of the corresponding author: a.mostafa@ concordia.ca

Telephone: +1 (514) 8482424 ext. 3146

Fax: +1 (514) $848-3175$

\begin{abstract}
In this work, wetting behavior of Ti-20Zr-20Cu-20Ni brazing filler on Ti-6Al-4V substrate was studied using sessile drop technique. Effects of the substrate surface roughness, $\mathrm{R}_{\mathrm{a}}$ of $\sim 0.40$ and $0.08 \mu \mathrm{m}$, and heating scheme on wetting and spreading of the filler metal were evaluated. The wetting mechanism was investigated by the combination of cooling technique, thermal, compositional, and microstructural analysis. This was performed using a heat-flux DSC and an SEM equipped with EDS. The degree of wetting was evaluated by measuring the apparent dynamic contact angle between the filler drop and substrate surface and by calculating the drop spread ratio. The surface roughness of the substrate was found to have little or no effect on the final apparent contact angle. The wetting behavior of this system showed a reactive nature, because it involves dissolution of the substrate and formation of interfacial layers. Three heating schemes were used in the current study. While the high heating rate of $6.8{ }^{\circ} \mathrm{C} / \mathrm{s}$ was found to limit the metallurgical reaction between the substrate and the brazing filler, in the low heating rate scheme of $1.7{ }^{\circ} \mathrm{C} / \mathrm{s}$, more intense metallurgical reaction occurred between the brazing filler and the substrate. The high heating rate with soaking scheme is recommended for brazing, because it entails extensive spreading and limited metallurgical reaction between the brazing filler and the substrate.
\end{abstract}

Keywords: Ti-6Al-4V alloy, wetting, spreading, Brazing filler, reactive wetting 


\section{Introduction}

Titanium alloys are widely used for many applications in aerospace, biomedical, nuclear and chemical industries [1], because of their good heat and corrosion resistance, high strength to weight ratio (relative to steel), weldability and good mechanical properties at elevated temperature [2-4]. Conventional titanium alloys are usually classified into four grades based on their composition and the constituent phase that predominates at room temperature. These are: $\alpha-$, near- $\alpha, \alpha-\beta$ or $\beta$ alloys $[5,6]$. Ti-6Al-4V (wt.\%) is the most widely used titanium alloy, accounting for around $60 \%$ of the total usage of $\mathrm{Ti}$ [7], and it is a typical example of $\alpha-\beta$ titanium alloys. Brazing of titanium and its alloys became much more prominent in the past few decades [7]. Quite a number of pure metals and alloys are used as filler materials in brazing processes [8]. However, such filler material must be able to wet the base metal and produce a joint with the required service capabilities and properties $[9,10]$. Wetting gives an indication of the extent of intimacy in contact between a liquid and a solid; making it an important behavior to evaluate the success of industrial operations such as brazing, soldering, coating and composite manufacturing [11-17]. The degree of wetting of a substrate by a liquid is usually quantified by the equilibrium contact angle, $\theta$, which the liquid metal drop forms on such a substrate [18-20]. The system is usually described as wetting or nonwetting if the contact angle is less or greater than $90^{\circ}$, respectively [21]. A detailed review on the progress made in wettability study could be found in the work done by Komolafe and Medraj [22].

Titanium joints can be brazed with Ag-based brazing fillers [2, 23, 24], but such joints usually have lower strength and reduced corrosion resistance, compared with similar joints brazed with Ti-or Zr-based fillers [6, 25, 26]. Chang and Shiue [27]studied the wetting behavior of Ti-15Cu$15 \mathrm{Ni}$ brazing filler on Ti-6Al-4V. However, the wetting mechanism was never discussed, nor the wetting/spreading contact angle vs. time graph was presented. It was only reported that the brazing filler could wet Ti-6Al-4V substrate at $970{ }^{\circ} \mathrm{C}$. According to Chang et al. [7], it is preferred to keep the brazing temperature of $\alpha-\beta$ titanium alloys below the $\beta$-transus temperature, which is reported to vary from 900 to $1040{ }^{\circ} \mathrm{C}$ for Ti-6Al-4V, in order to maintain the carefully engineered microstructure. Therefore, it might be impossible to achieve this with Ti-15Cu-15Ni brazing filler, because its solidus and liquidus temperatures are $910{ }^{\circ} \mathrm{C}$ and $960{ }^{\circ} \mathrm{C}$, respectively [27]. Equally, the tendency of Ti-20Zr-20Cu-20Ni brazing filler to wet Ti-6Al-4V alloy was studied by Chung et al. [28]. Only the final (static) contact angle of the filler metal on the substrate was determined, as $24^{\circ}$, by observing the filler-substrate cross-section using scanning electron microscope (SEM). 
The contact angle vs. time graph for the wetting/spreading was not presented, neither the wetting mechanism was discussed.

The aim of this work is to contribute to the understanding of the wetting behavior of the Ti20Zr-20Cu-20Ni (wt.\%) brazing filler on Ti-6Al-4V substrates. This system has been chosen because of the brazing filler's low solidus and liquidus temperatures of $848^{\circ} \mathrm{C}$ and $856^{\circ} \mathrm{C}$ [29], respectively. Conventional sessile drop experimental technique was used, being the closest to simulating the real industrial brazing process. The influence of substrate surface roughness and heating rate scheme on the wetting behavior were also evaluated.

\section{Experimental Procedure}

A sheet of Ti-6Al-4V alloy with dimensions of $12 \times 12 \times 1 \mathrm{~mm}$ was used to fabricate substrates for the experiments. In order to evaluate the influence of the substrate surface roughness on the wetting behavior of the brazing filler, some of the samples were ground up to 120 grit SiC paper to generate a relatively rough surface. The remaining samples were ground up to 1200 grit $\mathrm{SiC}$ paper to generate a relatively smooth surface. Samples were ground in two perpendicular directions on the plane surface of the substrate to ensure a relatively equal roughness values.

The brazing filler alloy Ti-20Zr-20Cu-20Ni was supplied by Lucas-Milhaulpt ${ }^{\circledR}$ (Wisconsin, USA) in form of foil ( $50 \mu \mathrm{m}$ thick). The microstructure of this filler was examined and analysed using Hitachi S-3400N scanning electron microscope, equipped with energy dispersive X-ray spectrometer (EDS). The foil was remelted, into a sphere shape, under an argon atmosphere, in an arc-melting furnace. The average diameter of the brazing/wetting ball used in this work was kept to $\sim 1 \mathrm{~mm}$ in order to minimize the effect of gravitational force on the wetting/spreading process.

Thermal analysis of the brazing filler, for both as received and remelted foils (ball-shaped), was performed using a SETARAM heat-flux differential scanning calorimeter (DSC) equipped with thermogravitometer (TG). The samples were placed in alumina crucibles and heated to $950{ }^{\circ} \mathrm{C}$ using $5{ }^{\circ} \mathrm{C} / \mathrm{min}$ heating and cooling rates. Thermal analysis was used to reveal the influence of foil-remelting step on the alloy composition by monitoring the position of the phase transformation peaks during heating and cooling cycles. Moreover, it will detect if the ball-shaped brazing filler, used in this work, could truly replicate and simulate the real industrial brazing, which is normally carried out using a foil-shaped brazing filler.

The wetting experiments were performed in a custom-made apparatus shown in Figure 1 (a). The schematic illustration of the main parts of the system setup are shown in Figure 1 (b). The 
tube of the furnace is made out of alumina and it is divided into two zones: hot and cold. The temperature inside the cold zone was reduced using water cooling jackets at both ends of the tube and is used for rapid cooling of the samples. The core of the tube remained uncooled and referred to as the hot zone in this work. The dynamic image of the spreading droplet was acquired by a high-speed camera (264 frames per second) through a transparent window. The experiment was done under a high vacuum of $1 \times 10^{-6}$ Torr, which was achieved using a diffusion pump as indicated in Figure 1(a). Each sample was ultrasonically cleaned in an acetone bath for 15 minutes and dried before each test to remove any contaminating residues. The target temperature for all experiments was $900{ }^{\circ} \mathrm{C}$ and each run lasted for $900 \mathrm{~s}$ after the onset of melting of the brazing filler. However, some samples were cooled at the early stages of wetting in order to understand the wetting mechanism in this system.

(a)

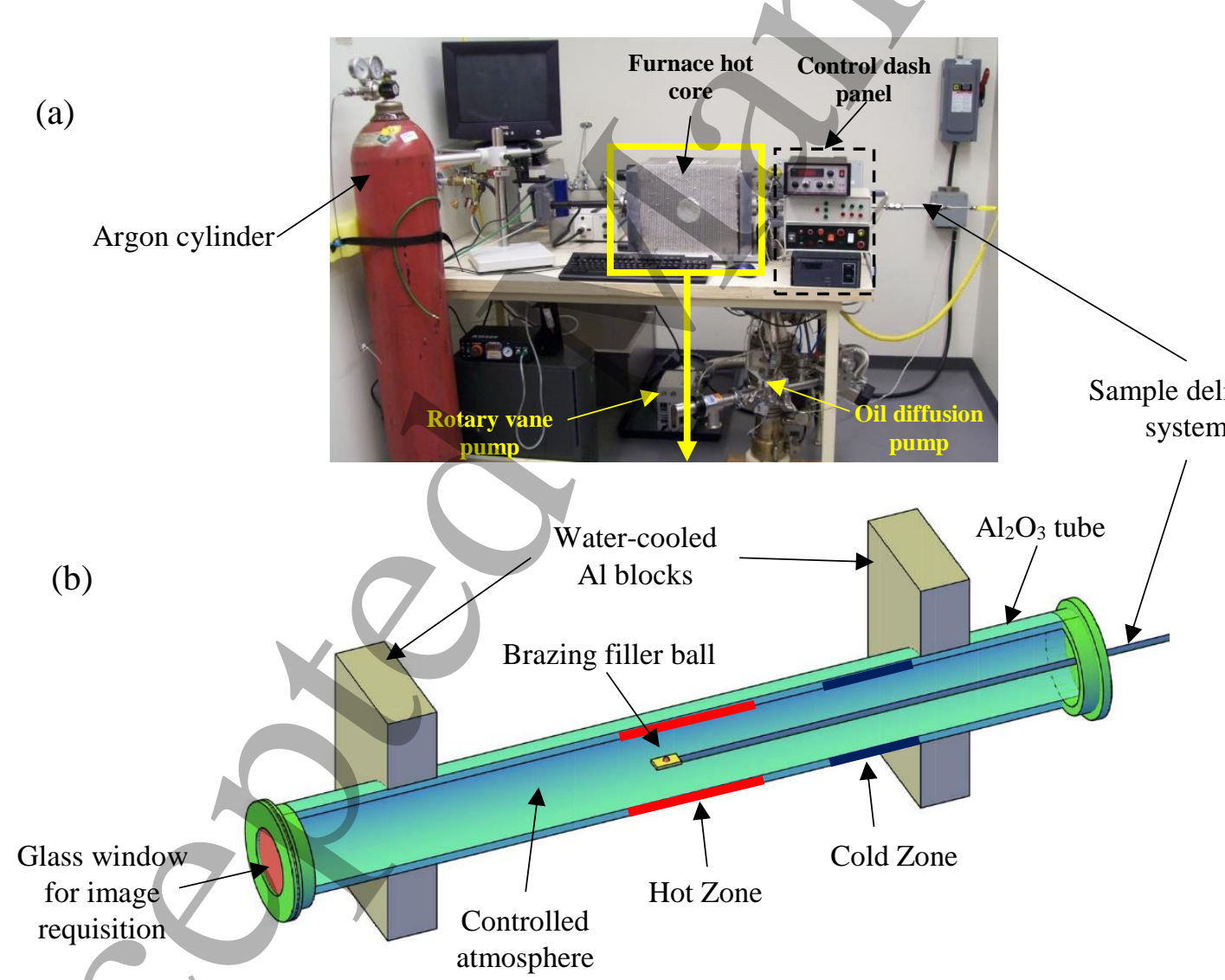

Figure 1. (a) The wetting apparatus set-up and (b) schematic illustration showing the main parts of the heating system in the wetting apparatus

Three heating schemes, presented in Figure 2, were used in this work to provide better understanding of the wetting/spreading behavior of the filler material at different heating rates. 
The high heating rate scheme was achieved by keeping the sample (the substrate and the $\sim 1$ $\mathrm{mm}$ brazing filler ball) at the water-cooled end (cold zone), while heating the furnace hot core (hot zone) to the required test temperature $\left(900^{\circ} \mathrm{C}\right)$. The sample was kept at the cold zone $\left(\sim 350{ }^{\circ} \mathrm{C}\right)$ for about 40 minutes to allow the hot zone to reach uniform and steady-state temperature. After this time period, the sample was then pushed straight, using the sample delivery unit, to the furnace hot core centre (hot zone), to carry out the wetting test. With this scheme, the average heating rate to the point of melting of the brazing filler ball was $6.8^{\circ} \mathrm{C} / \mathrm{s}$. A typical heating curve of this heating scheme is shown in Figure 2a.

For the high heating rate with intermediate soaking scheme, after keeping the sample at the water-cooled end for about 30 minutes, the sample was placed at the edge of the hot zone to heat it to $650{ }^{\circ} \mathrm{C}$. The sample was kept there between 300 and 600 seconds to allow both the ball and the substrate to reach thermal equilibrium. After this soaking stage, the sample was then pushed all the way to the centre of the furnace (hot zone), to carry out the wetting test. With this scheme, the average heating rate to the point of melting of the brazing filler ball was $5.6^{\circ} \mathrm{C} / \mathrm{s}$. A typical heating curve of this heating scheme is shown in Figure $2 b$.

With respect to the low heating rate scheme, the sample was heated up to the target temperature $\left(900{ }^{\circ} \mathrm{C}\right)$ from room temperature. For this scheme, the sample was placed in the middle core of the furnace and the average heating rate to the point of melting was $1.7^{\circ} \mathrm{C} / \mathrm{s}$. A typical curve of this heating scheme is shown in Figure 2c.

The degree of wetting of the substrate by the brazing filler was quantified by measuring two different responses, the apparent dynamic contact angle $(\theta)$ and the spread ratio. Basic procedure of image processing was used to determine the free surface of the droplet and its reflection on the substrate surface. A sequence of the side view images of the wetting process, acquired by the high speed camera, were captured and converted to a black and white scale to obtain the line diagram as demonstrated in Figure 3. The line diagrams were then used to determine the apparent dynamic contact angle and dynamic spreading diameter. The triple point was subsequently determined and a tangent was drawn at this point, relative to the free surface of the droplet. The angle between the tangent and the line of symmetry of the droplet was taken as the dynamic apparent contact angle. The spread ratio represents the ratio of the instantaneous base diameter of the spreading droplet $(D)$ to the initial diameter of the brazing ball $\left(D_{o}\right)$ used for the experimental test. The diameter of 
the droplet was extracted with the aid of a modified version of an algorithm in Matlab [30]. Both $\theta$ and $D$ were determined with an accuracy of $\pm 2^{\circ}$ and $\pm 2 \%$, respectively.
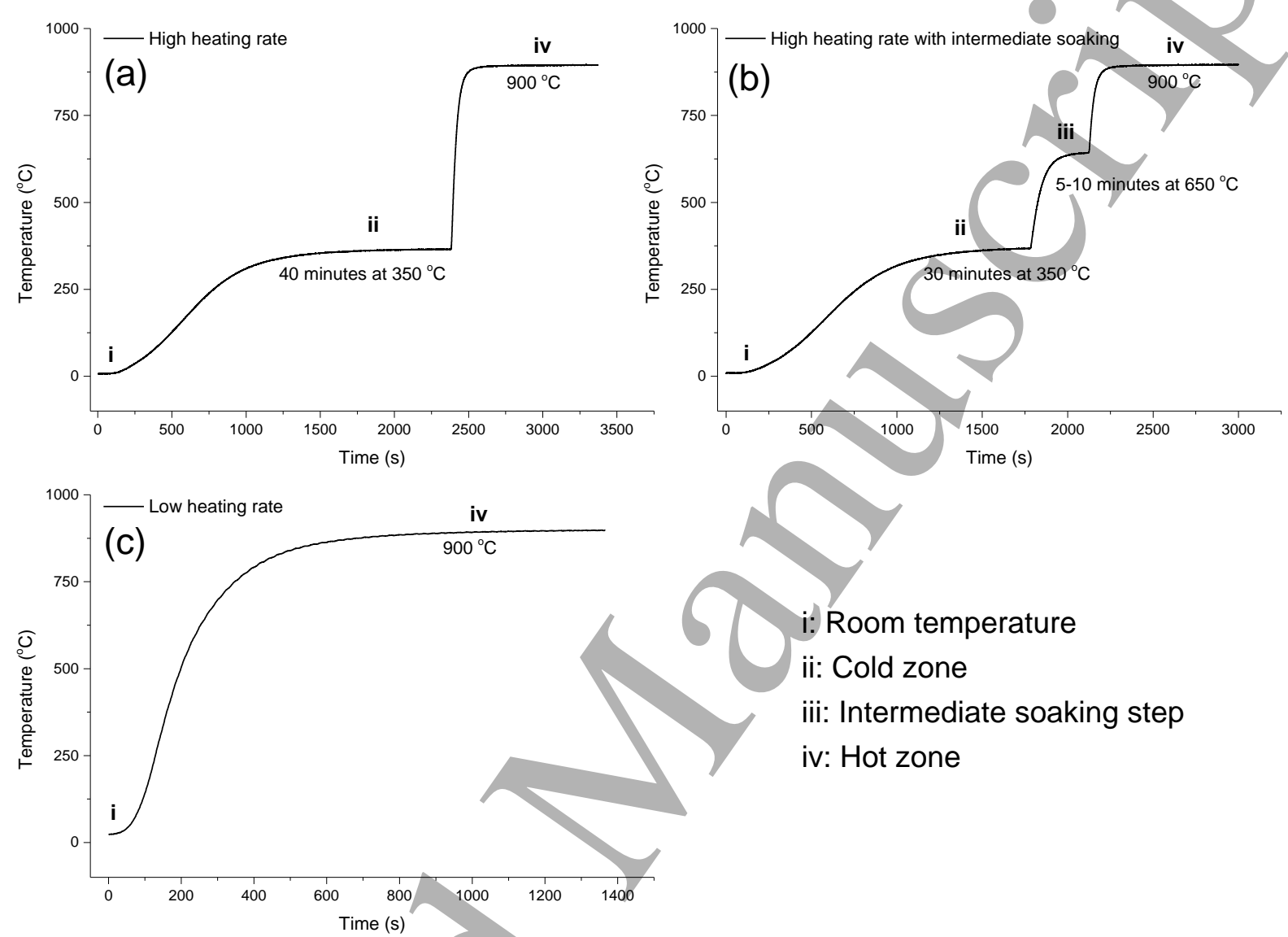

i: Room temperature

ii: Cold zone

iii: Intermediate soaking step

iv: Hot zone

Figure 2. Typical heating curves of (a) the high heating rate $\left(6.8^{\circ} \mathrm{C} / \mathrm{s}\right)$ scheme; (b) the high heating rate $(5.6$ $\left.{ }^{\circ} \mathrm{C} / \mathrm{s}\right)$ with intermediate soaking scheme; (c) the low heating rate $\left(1.7^{\circ} \mathrm{C} / \mathrm{s}\right)$ scheme.
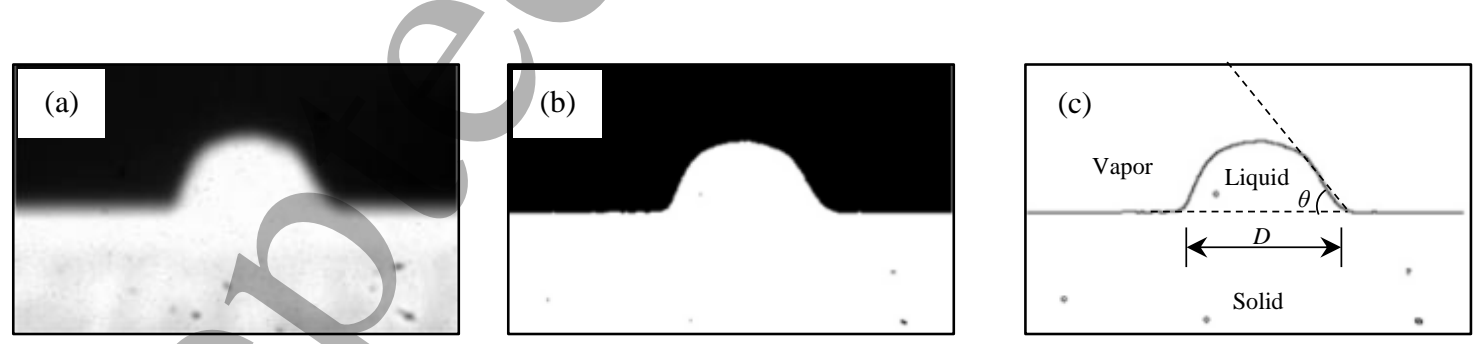

Figure 3. Steps used for image analysis to calculate the contact angle, $\theta$, and the diameter, $D$, of the spreading droplet; (a) original image; (b) threshold determination; (c) line diagram for edge detection

Microstructural analyses of fully annealed samples and those cooled at key points and times were performed to elaborate on the understanding of the wetting mechanism in this system. It was done with the aid of an optical and a scanning electron microscopes. The samples were sectioned perpendicularly to the interface, using a low speed diamond saw. The sectioned samples were 
gradually ground up to 1200 grit using SiC papers and then polished using $1 \mu \mathrm{m}$ alcohol-based diamond suspension.

\section{Results and Discussions}

\subsection{Surface roughness values}

Typical examples of the average roughness values, $R_{a}$, obtained for samples ground with 120 grit and 1200 grit SiC papers are shown in Tables 1 and 2, respectively. The two directions of measurement of the surface roughness, labeled $\mathrm{R}_{\mathrm{a}} 0^{\circ}$ and $\mathrm{R}_{\mathrm{a}} 90^{\circ}$, are perpendicular to each other. The roughness values were measured using Mitutoyo Surftest SJ-210 profilometer. Three tests were performed on each sample to ensure the repeatability of the test results.

Table 1. Average surface roughness values of a sample with a relatively rough surface ( 120 grit $\mathrm{SiC}$ paper)

\begin{tabular}{|c|c|c|}
\hline Test & $\mathrm{R}_{\mathrm{a}} 0^{\circ}(\mu \mathrm{m})$ & $\mathrm{R}_{\mathrm{a}} 90^{\circ}(\mu \mathrm{m})$ \\
\hline 1 & 0.44 & 0.42 \\
\hline 2 & 0.40 & 0.41 \\
\hline 3 & 0.37 & 0.32 \\
\hline
\end{tabular}

Table 2. Average surface roughness values of a sample with a relatively smooth surface (1200 grit SiC paper)

\begin{tabular}{|c|c|c|}
\hline Test & $\mathrm{R}_{\mathrm{a}} 0^{\circ}(\mu \mathrm{m})$ & $\mathrm{R}_{\mathrm{a}} 90^{\circ}(\mu \mathrm{m})$ \\
\hline 1 & 0.08 & 0.08 \\
\hline 2 & 0.08 & 0.11 \\
\hline 3 & 0.09 & 0.09 \\
\hline
\end{tabular}

\subsection{Microstructure of the filler material}

The SEM micrograph of the cross-section of the filler material showed the presence of seven layers as can be seen in Figure 4. Elemental analysis was performed using EDS line scan. The result of the EDS line scan across different layers of the filler material is shown in Figure 5. EDS spot analyses were performed on each layer, to determine its chemical composition. Layers 1 and 7 are an alloy, containing $50 \mathrm{Cu}-50 \mathrm{Ni}$ at.\%, layers 2 and 6 are essentially pure $\mathrm{Zr}$, layers 3 and 5 are pure $\mathrm{Cu}$, while layer 4 is pure Ti. The EDS results showed that the filler foil contains layers of pure elements such as $\mathrm{Cu}, \mathrm{Ti}$ and $\mathrm{Zr}$, which have high melting temperatures as 1083, 1660 and 1852 ${ }^{\circ} \mathrm{C}$, respectively. This might give an impression that the target temperature $\left(900{ }^{\circ} \mathrm{C}\right)$ in this work will not be sufficient to melt the filler alloy. However, in all experiments, the filler foil was melted and liquid phase was formed. DSC experiments were carried out to determine the melting 
temperature and other phase transformations of the filler alloy. In the following section, the foil melting mechanism will be discussed based on the DSC results and phase diagram data [32-35].

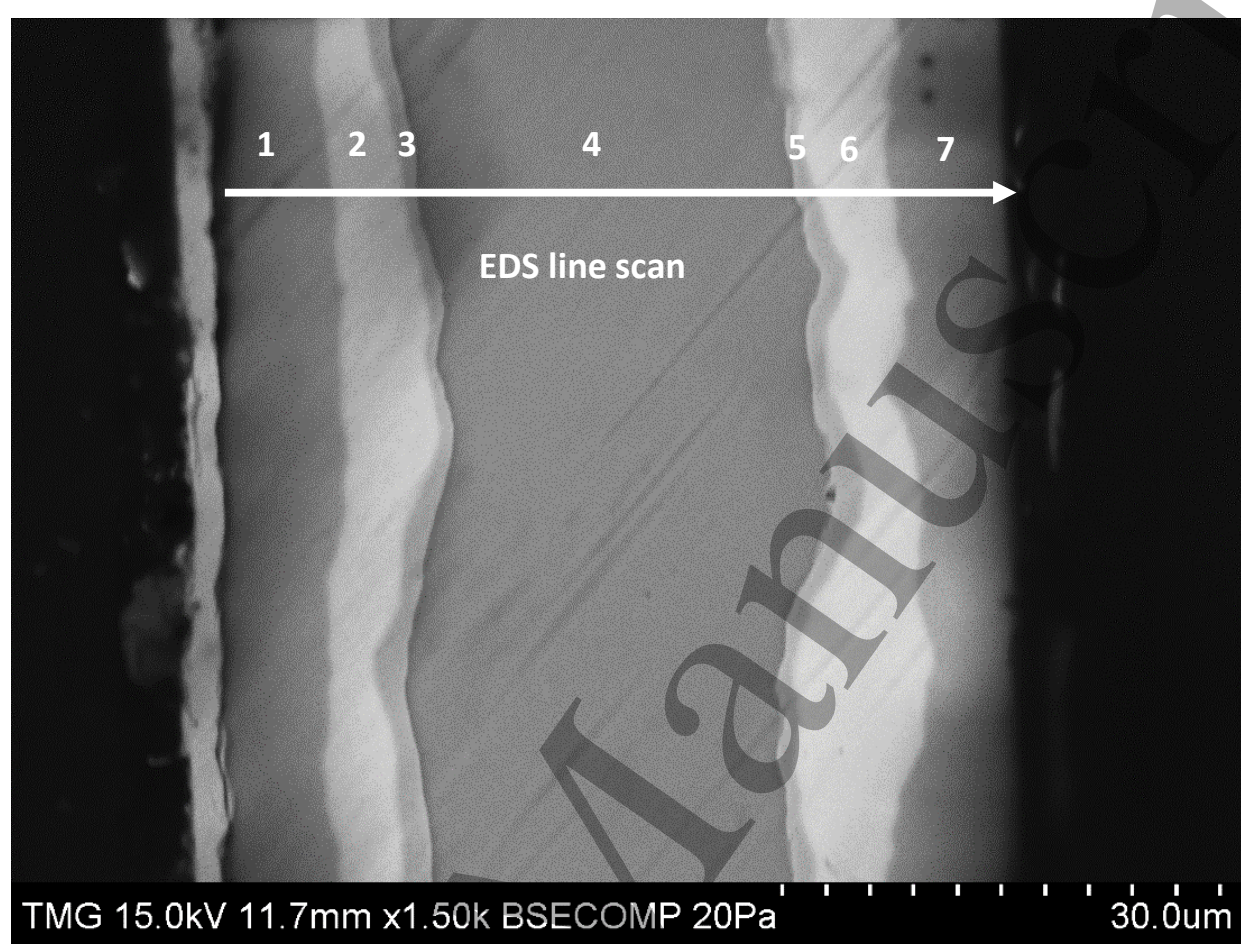

Figure 4. SEM micrograph of the cross-section of the layered structure of the brazing filler. The numbers on it correspond to those on the EDS line-scan of Figure 5.

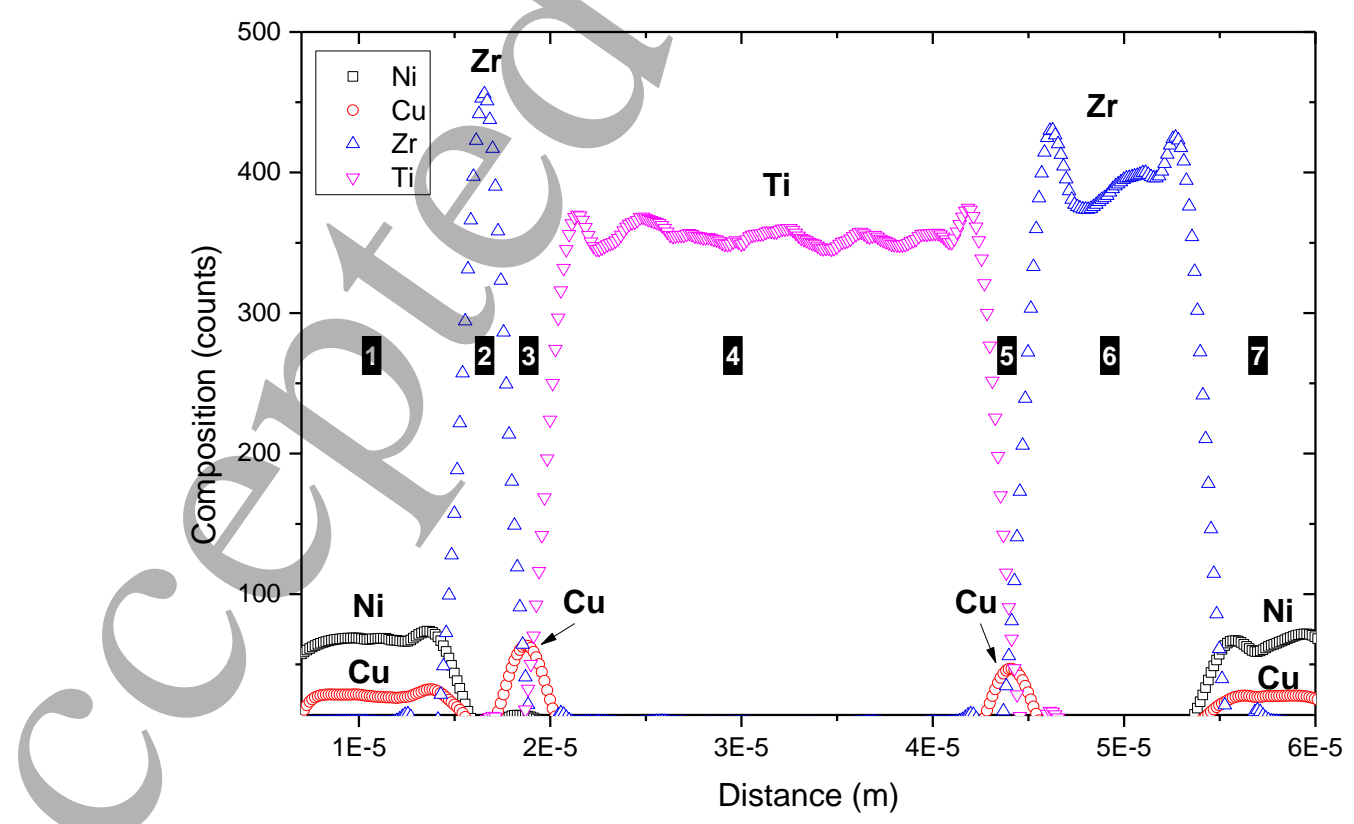

Figure 5. EDS line scan across different layers of the brazing filler. The numbers inside the shaded boxes correspond to the layers labeled in Figure 4. 


\subsection{DSC results}

Thermal analysis of the filler alloy, in both foil and ball shapes, was performed using DSC with heating and cooling rates of $5{ }^{\circ} \mathrm{C} / \mathrm{min}$. Both forms of the filler alloy were analyzed to verify whether the melting point of the alloy was influenced when the filler foil was remelted or not. The DSC results are shown in Figures 6 a-c. Figure 6 a presents the results obtained from the foil-shaped filler material in the first thermal cycle. During heating, the first response was observed at $835^{\circ} \mathrm{C}$ in the form of a small endothermic peak. This could be attributed to the geometrical changes of the foil upon heating and not due to reaching the solidus point, because the lowest liquid in this alloy system occurs at $850^{\circ} \mathrm{C}$ based on binary, ternary and multi-component phase diagrams data [32-35]. This peak was followed by a relatively strong exothermic peak, occurred between 840 and $846^{\circ} \mathrm{C}$, which might be attributed to the onset of melting of the foil. With continuous heating, another small endothermic peak, occurred at $873{ }^{\circ} \mathrm{C}$, representing the liquidus of the filler alloy. This was confirmed by the onset of the first exothermic peak (during cooling), which occurred at $871.5^{\circ} \mathrm{C}$. The second exothermic peak represents the solidus of the alloy system which occurred at $847^{\circ} \mathrm{C}$.

Figures $6 b$ and $c$ present the DSC results of the remelted foil (second DSC cycle of the foil presented in Figure 6a) and the arc-melting furnace-remelted (ball-shaped) foil, respectively. The solidus was determined as around $849^{\circ} \mathrm{C}$ in both cases. The higher end of the melting range of this foil was determined as $873{ }^{\circ} \mathrm{C} \pm 1$ in all DSC experiments. The results of the DSC experiments in Figure 6 a-c are very similar, which proves that the composition of the foil was not changed upon remelting. Thus, using the brazing ball in the current work is a true representation of the industrial brazing process that involves melting the filler only once. 

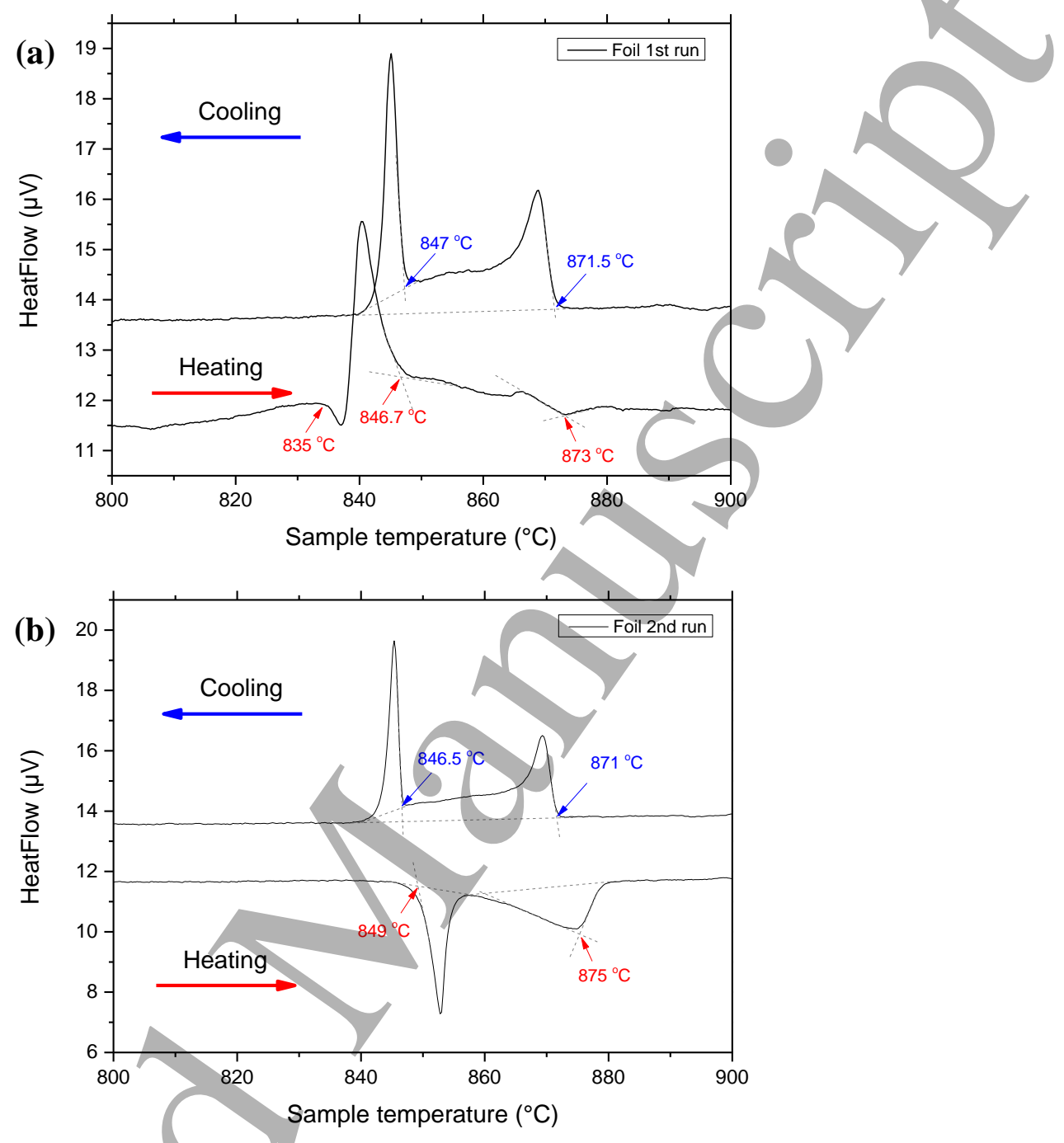

(c)

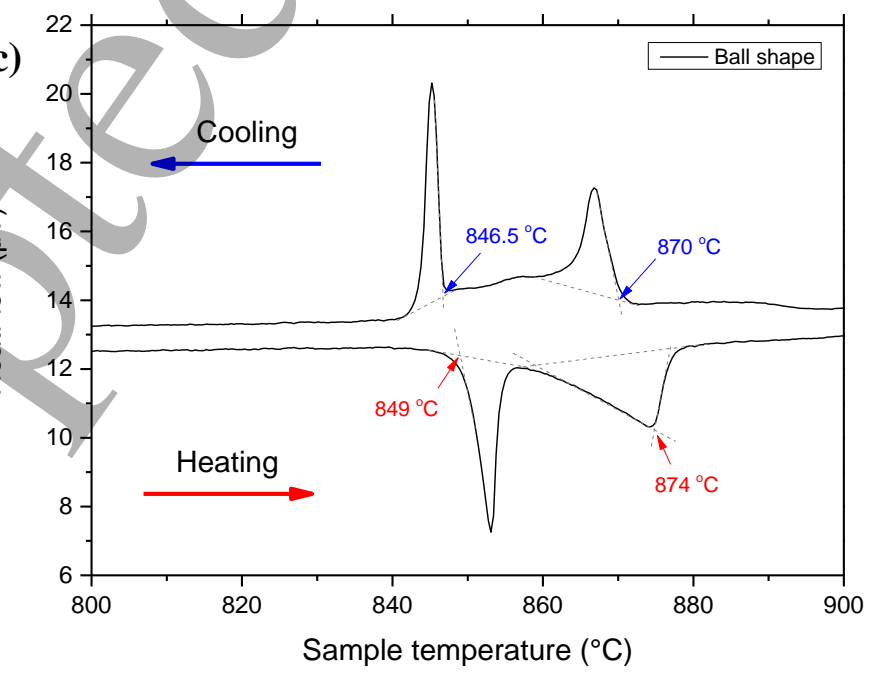

Figure 6. DSC results of (a) the first cycle of the foil-shaped filler material; (b) the second cycle of the foilshaped filler material (DSC-remelted); (c) the remelted foil material (ball-shaped) 


\subsection{Effect of the heating schemes on the wetting process}

The wetting results obtained under each heating scheme are presented below. The microstructural and surface roughness analyses are also discussed and presented with respect to each heating scheme.

\subsubsection{High heating rate $\left(6.5^{\circ} \mathrm{C} / \mathrm{s}\right)$ scheme}

The variation of the spread ratio with temperature and time are shown in Figures $7 \mathrm{a}$ and $\mathrm{b}$, respectively. The origin of the time scale of Figure $7 \mathrm{~b}$ indicates the time when melting started in relation to the temperature-time graph of the heating scheme (Figure 2). Similar time scale is used for other wetting graphs. In Figure 7, a very high wetting/spreading rate was observed after melting. The spread ratio increased in a monotonous manner. After this fast spreading stage, the slope of the curve decreased substantially and the spread ratio vs. time graph effectively reached a plateau. Similar trend was observed in the contact angle vs. time graph of the same sample. The average value of the final apparent contact angle was $37^{\circ}$. This fast spreading/wetting has also been observed in other reactive wetting systems in the literature [36]. This stage of wetting/spreading is usually referred to as the "primary spreading" stage [37, 38], which is characterized with fast drop in the contact angle as shown in Figure 8a (A-B). The rapid advancement of the triple point of the molten drop at this stage is attributed to the uncompensated Young's force, and reaction is not expected to exert a first-order or dominant effect in the triple point region, thus, making this regime of spreading to be termed non-reactive [31, 39]. The industrial implication of this very high wetting/spreading rate is that successful brazing can be done within a short period of time, using this brazing alloy and heating scheme. This is very significant, because in some cases, a very long brazing time has been found to have detrimental effects on the strength of the brazed joint [40].

Variation of the spread ratio with temperature (Figure 7a) indicates that noticeable wetting/spreading ceases before the temperature reaches $900{ }^{\circ} \mathrm{C}$. This is very significant for industrial application, because it shows that brazing, using this filler metal, can be done below the lower limit of the beta transus temperature which varies from 900 to $1040{ }^{\circ} \mathrm{C}$ for $\alpha-\beta$ titanium alloys [7]. The result under this heating scheme gives a fair reflection of what is likely to happen if the high heating rate infrared brazing procedure is employed for industrial brazing of Ti-6Al-4V with Ti-20Zr-20Cu-20Ni brazing filler [27]. 

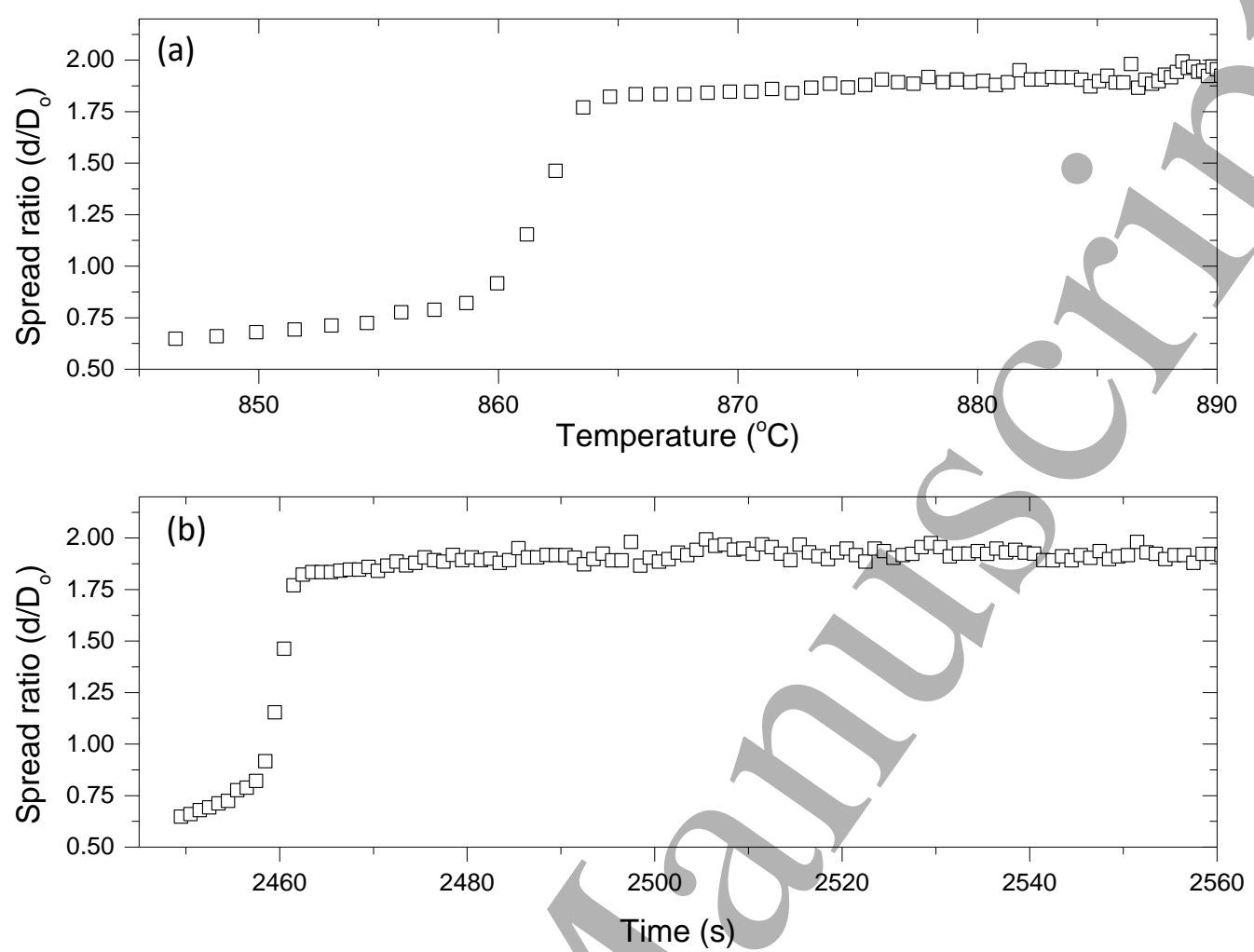

Figure 7. Variations of spread ratio under high heating rate $\left(6.8^{\circ} \mathrm{C} / \mathrm{s}\right)$ scheme (a) with temperature and (b) with time.

The final macrograph of the wetting sample is inset in Figure 8a. The final diameter was measured and used to obtain the aspect ratio from this macrograph, and the same procedure was followed for other samples. The edge of the brazing filler droplet is fairly smooth, which suggests that the reaction between the brazing filler and substrate was not intense. The microstructural analysis of samples tested in different heating schemes is discussed in section 3.5.

\subsubsection{Low heating rate $\left(1.7^{\circ} \mathrm{C} / \mathrm{s}\right)$ scheme}

Figure $8 \mathrm{~b}$ shows the wetting behavior of a sample used under the low heating rate $\left(1.7{ }^{\circ} \mathrm{C} / \mathrm{s}\right)$ scheme. Three distinct wetting stages could be observed in this graph. The first stage occurs between points $\mathrm{A}$ and $\mathrm{B}$, with a relatively high spreading rate (primary spreading). At the end of this stage, the spreading droplet seems to form a stable contact angle (between points B and C), for few seconds, ranging between $110-115^{\circ}$ on the substrate. Similar spreading stage was observed in the spreading of $\mathrm{Cu}-\mathrm{Si}$ alloys on $\mathrm{SiC}$ substrates that had been deliberately oxidized [41]. The equilibrium contact angle of about $100^{\circ}$ obtained at that stage in the $\mathrm{Cu}-\mathrm{Si} / \mathrm{SiC}$ system was found to be about the same as the equilibrium contact angle of $\mathrm{Cu}-\mathrm{Si}$ alloy on vitreous $\mathrm{SiO}_{2}$ substrates 
[41]. It implies that the transient steady contact angle, obtained at this stage in our system, might actually be the equilibrium contact angle of the brazing filler on the oxide layer present on the substrate. However, no further work was done to establish the nature of the oxide or the deoxidation mechanism at the triple line.

The second stage of spreading occurs between points $C$ and D. This stage is characterized with continuously decreasing spreading rate. The contact angle at the end of this stage was about $33^{\circ}$, very close to the average value of the final apparent contact angle $\left(37^{\circ}\right)$ obtained under the high heating rate scheme. The last distinct spreading/wetting stage occurred between points D and E. This stage is so called secondary spreading stage. At this stage, the wetting is linear and the spreading rate is considerably lower than the two previous stages. Noticeable spreading ceases between points $\mathrm{E}$ and $\mathrm{F}$, with the average value of the final apparent contact angle being $15^{\circ}$.

These distinct spreading stages, observed under low heating rate scheme, are not synonymous to this system alone. Similar distinct spreading stages have been observed in other systems in the literature [42-44]. Dezellus et al. [45] labeled the spreading in the second stage (C-D) as "decreasing rate spreading (DRS)". The velocity of the triple line in the DRS stage has been found to depend solely on the instantaneous contact angle [44]. At this stage, direct contact between the substrate and the spreading droplet is expected, leading to high dissolution rate and strong coupling between the spreading kinetics of the droplet and the process of atomic transfer at the filler/substrate contact line [46].

In the secondary spreading stage (D-E), a reaction is expected to occur between the brazing filler droplet and substrate. Thus, the rate of the linear spreading stage is expected to be close to the radial growth rate of the intermetallic components, which form a remarkable diffusion layer at the contact line [46]. The triple line will advance with the leading edge of the diffusion layer, just as it was in the $\mathrm{Sn} / \mathrm{Au}$ wetting study [38], in which $\mathrm{AuSn}_{4}$ compound was formed as an interfacial reaction product.

The final macrograph of the wetting sample under this low heating rate scheme is shown in Figure $8 \mathrm{~b}$ (inset). From the macrograph, it could be seen that the substrate was oxidized. The rough and irregular edge of the droplet is an indication of intense reaction between the brazing filler and the substrate. The microstructural analysis of the sample in this heating scheme is discussed in the following section. 


\subsubsection{High heating rate $\left(5.6^{\circ} \mathrm{C} / \mathrm{s}\right)$ scheme with intermediate soaking at $650{ }^{\circ} \mathrm{C}$}

This heating scheme was used to evaluate the effect of soaking or preheating and its duration on the wetting of the substrate by the brazing filler. This will also ensure that both the substrate and the brazing filler are at the same uniform and equilibrium temperature before heating up to the test temperature. A soaking temperature of $650^{\circ} \mathrm{C}$, well below the solidus $\left(847^{\circ} \mathrm{C}\right)$ of the brazing filler, was used. The soaking time was performed for 5 and 10 minutes.

Figures $8 \mathrm{c}$ and $\mathrm{d}$ show the wetting behavior of the two samples under this heating scheme, soaked for 5 and 10 minutes, respectively. With respect to the sample that was soaked for 5 minutes, a drop in the contact angle of the brazing droplet from around $140^{\circ}$ to around $120^{\circ}$ could be observed. This spreading stage was followed by a primary spreading between points A and B, which shows a very fast and continuous drop in the contact angle of the droplet. The last wetting stage was between points $\mathrm{B}$ and $\mathrm{C}$. The spreading in this last stage can be likened to the decreasing rate spreading. After point $\mathrm{C}$, noticeable spreading could not be observed. The average value of the final apparent contact angle was $17^{\circ}$.

For the sample soaked for 10 minutes, three spreading stages, similar to those in Figure $8 \mathrm{~b}$, were observed. The first spreading stage involved the drop in the contact angle of the droplet from about $140^{\circ}$ to a transient steady contact angle of about $120^{\circ}$ (A-B), similar to that observed in Figure $8 \mathrm{~b}$. This spreading stage was followed by another spreading stage with a continuously decreasing rate spreading (C-D), with a noticeable secondary spreading afterwards (D-E). The spreading ceased with an average final apparent contact angle of $19^{\circ}$. The degree of spreading in both samples, as seen from both Figures $8 \mathrm{c}$ and $\mathrm{d}$, is quite similar, despite the differences in the soaking time and the kinetics of spreading. From practical point of view, it implies that if this heating scheme is used for brazing Ti-6Al-4V substrate with Ti-20Zr-20Cu-20Ni brazing filler, good wetting could be achieved. However, the longer the soaking time, the more intense the metallurgical reaction between the brazing filler and the substrate will be. 

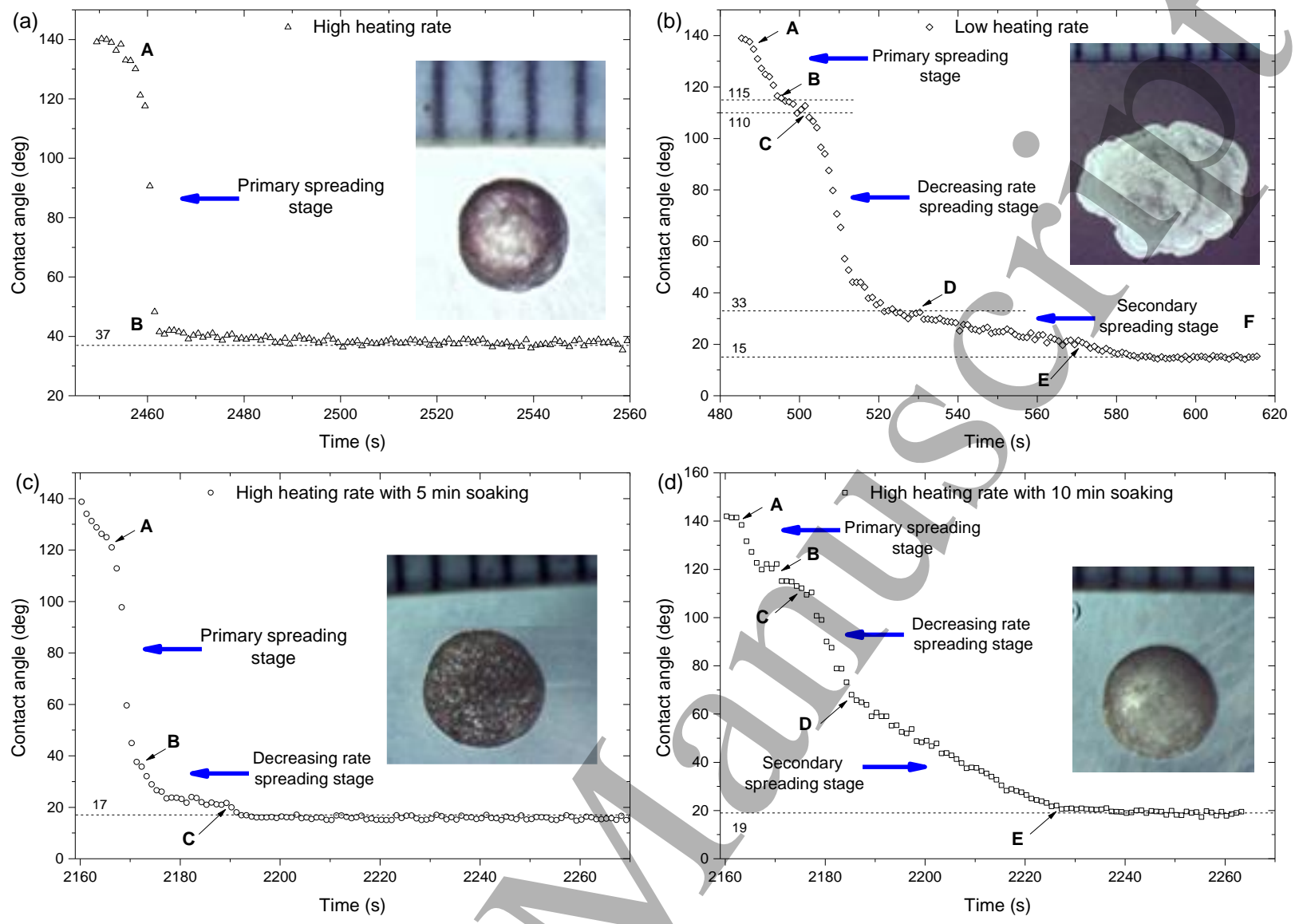

Figure 8. Variation of contact angle with time under (a) high heating rate; (b) low heating rate; (c) high heating rate with 5 minutes soaking at $650{ }^{\circ} \mathrm{C}$; (d) high heating rate with 10 minutes soaking at $650{ }^{\circ} \mathrm{C}$. The final macrographs of the samples under each heating scheme are embedded in each corresponding plot.

It is worth noting that the contact angle with time plot for high heating rate with 5 minutes soaking, (Figure 8c) looks similar to that for the high heating rate plot (Figure 8a). However, the final apparent contact angle in the soaked sample is lower. This shows that the high heating rate scheme with 5-minute soaking time combines the advantages of enhanced wetting/spreading, limited metallurgical reaction between the substrate and the brazing filler and reduced brazing time. On the other hand, the high heating rate scheme with 10 minutes soaking plot (Figure 8d) behaves in the same way as that for the low heating rate plot (Figure 8b). It implies that longer soaking time or lower heating rate might increase brazing time and enhance metallurgical reaction between the substrate and the brazing filler. 


\subsection{Microstructural analysis}

\subsubsection{High heating rate}

The micrographs of the wetting sample under the high heating rate $\left(6.8^{\circ} \mathrm{C} / \mathrm{s}\right)$ scheme, after $900 \mathrm{~s}$ of wetting test, are shown in Figure 9.
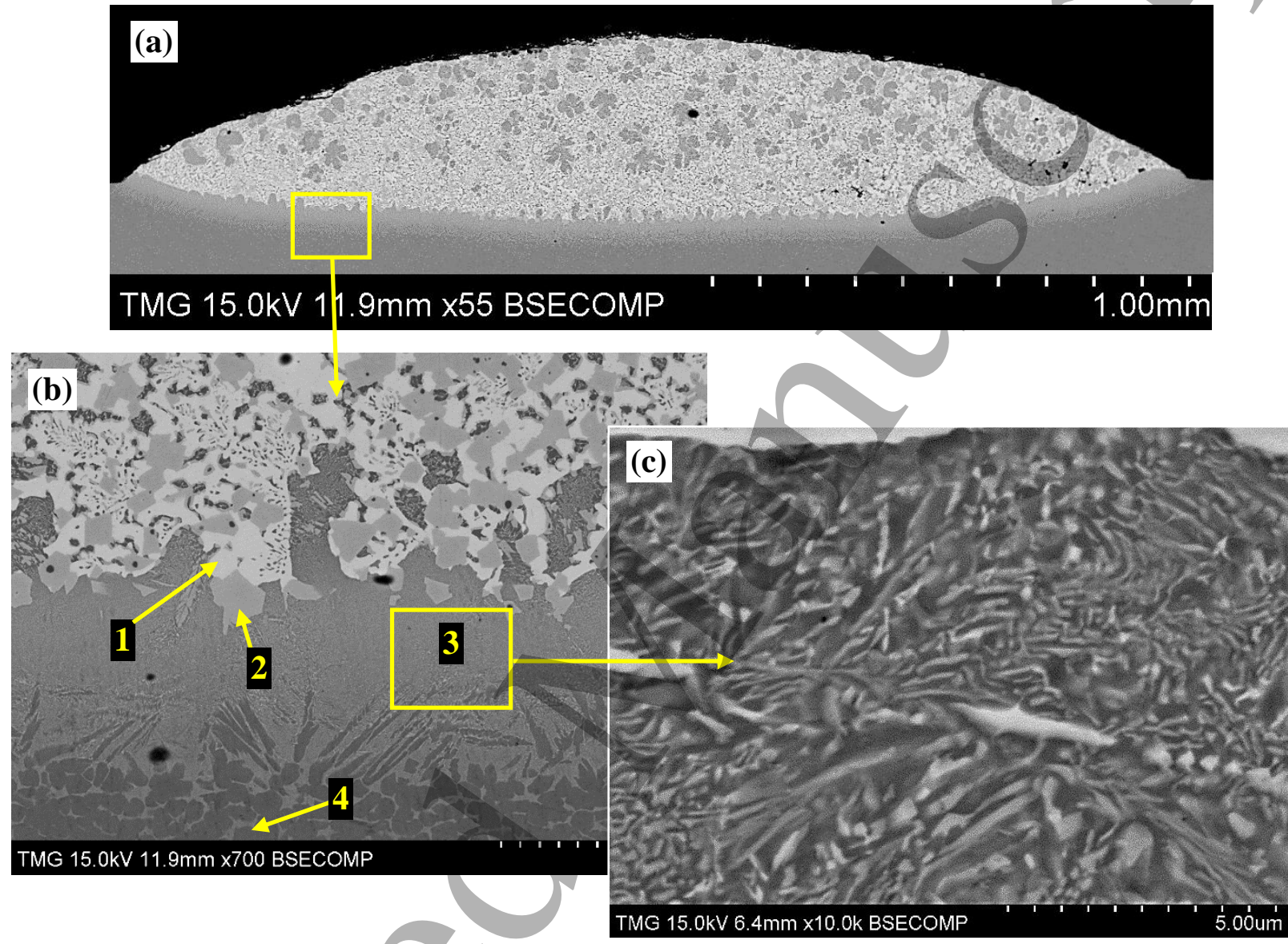

Figure 9. SEM back scattered electron image of (a) the high heating rate wetting condition; (b) magnified portion shows the interfacial layer. The numbers represent the EDS spot analysis and correspond to those in Table 3. (c) An enlarged view showing the eutectoid structure.

Figure 9a shows a non-planar intermetallic interface between the brazing filler and the substrate after the high heating rate wetting condition indicating the dissolution of the substrate into the brazing filler. The interface is fairly uniformly curved, which is a typical liquid/solid reaction interface [47]. A continuous layer is formed at the interface between the substrate and the brazing filler, with an average thickness of $45 \mu \mathrm{m}$. An enlarged view of the substrate/filler contacting line is shown in Figure 9b. A remarkable eutectoid structure, comprised of fine layers, could be seen on the substrate/filler reaction front as shown in Figure 9c. The eutectoid reaction is a solid-tosolid phase transformation and occurs when one solid transforms to two solids, which was believed to occur during cooling cycles. An EDS spot analysis was performed at points 1 to 4 in Figure $9 \mathrm{~b}$ 
to give the chemical composition of the intermetallics and the eutectoid. The result of this analysis is given in Table 3. The EDS chemical composition analysis show that the eutectoid is rich in Ti. In order to understand the mechanism behind the formation of this structure at the interfacial layer under the high heating rate scheme, it is important to look deeper into the mode of transfer of the solute in the liquid filler. The dissolved substrate species are transported in the liquid filler by both diffusion and convection mechanisms [37]. However, the downward conyective flow of the liquid at the very early stage of the wetting process, due to the initial melting of the wetting ball, is expected to be faster than the diffusive transport of the solute into the substrate [37]. The fast convective flow leads to change the chemical composition of both substrate and filler at the contact line, relative to the far-ends of the bulk substrate and filler melt, respectively. Table 3 indicates that the eutectoid composition is enriched with $\mathrm{Ti}$ due to the formation of $\mathrm{Ti}_{2} \mathrm{Ni}$ and $\mathrm{Ti}_{2} \mathrm{Cu}$ intermetallics. These intermetallic compounds are known to have high melting points $\left(\mathrm{Ti}_{2} \mathrm{Ni}=984^{\circ} \mathrm{C}\right.$ and $\left.\mathrm{Ti}_{2} \mathrm{Cu}=990^{\circ} \mathrm{C}\right)$, which could lead to form the $\beta \mathrm{Ti}+\left(\mathrm{Ti}_{2} \mathrm{Ni}\right.$ or $\left.\mathrm{Ti}_{2} \mathrm{Cu}\right)$ eutectic at the substrate/filler contacting line through isothermal solidification of the brazing joint. However, with further cooling, $\beta \mathrm{Ti}$ decomposes eutectoidally in Ti-Ni and Ti-Cu systems at $765{ }^{\circ} \mathrm{C}$ and 790 ${ }^{\circ} \mathrm{C}$, respectively. This concept was also proposed in the brazing of Ti and Ti-6Al-4V using Ti- and Zr-based amorphous fillers [26, 40].

Table 3. EDS analysis of the intermetallic compounds presented in Figure $9 \mathrm{~b}$ in atomic \%.

\begin{tabular}{|c|c|c|c|c|c|c|}
\hline Point & $\mathbf{A l}$ & $\mathbf{T i}$ & $\mathbf{V}$ & $\mathbf{N i}$ & $\mathbf{C u}$ & $\mathbf{Z r}$ \\
\hline 1 & 4.04 & 43.70 & - & 16.97 & 17.7 & 17.58 \\
\hline 2 & 1.00 & 58.46 & - & 21.98 & 11.07 & 6.50 \\
\hline 3 & 5.13 & 75.24 & 2.61 & 4.93 & 7.15 & 4.94 \\
\hline 4 & 11.43 & 86.46 & 2.11 & - & - & - \\
\hline
\end{tabular}

Although this is a multi-component system, a quick glance at the $\{\mathrm{Cu}, \mathrm{Ni}\}$-Ti binary phase diagrams [26] might be helpful in understanding the formation of such eutectoid microstructure. Due to the isothermal solidification of the brazing joint melt, the primary $\beta$-Ti forms at the brazing temperature of $900^{\circ} \mathrm{C}$. Upon the brazing cooling cycle, $\beta$-Ti decomposes eutectoidally through the reaction $\beta-\mathrm{Ti} \rightarrow \alpha-\mathrm{Ti}+\left(\mathrm{Ti}_{2} \mathrm{Ni}\right.$ or $\left.\mathrm{Ti}_{2} \mathrm{Cu}\right)$, forming $\mathrm{Ti}_{2} \mathrm{Ni}$ and/or $\mathrm{Ti}_{2} \mathrm{Cu}$ precipitates dispersed in $\alpha$ Ti matrix. Looking at the enlarged view of the interfacial layer in Figure 9c, it is obvious that it has a fine eutectoidal structure comprised of $\alpha-\mathrm{Ti}+\left(\mathrm{Ti}_{2} \mathrm{Ni}\right.$ or $\left.\mathrm{Ti}_{2} \mathrm{Cu}\right)$. The composition of each individual micro-constituent of the eutectoid was not possible to obtain, because their size is smaller than the EDS detector size. 
In order to further understand the phase transformations taking place in the Ti-6Al-4V/Ti-20Zr20Cr-20Ni brazing system, another sample was cooled only after $5 \mathrm{~s}$ from the onset of melting. The micrographs of this sample are shown in Figure 10. While a slight depression can be observed at the middle, the substrate surface remains essentially flat at the adjoining areas. This depression is due to the melting process of the brazing ball and the associated dissolution. An EDS line scan, shown in Figure 11 was performed from around the bottom of the droplet (Point A) towards the substrate (Point B) as illustrated in Figure 10b. Letters A and B in Figures 10 and 11 indicate the direction of the line scan. The results of EDS analysis reveal an increase in concentration of Ti, Al and $\mathrm{V}$ at the interface, relative to the bulk of the liquid. This increase is expected as the acquisition data points approach the Ti-6Al-4V substrate. This also provides an indication of mixing of the alloying elements from both the substrate and the wetting filler at the interface. The interfacial layer was also observed in the quenched sample, albeit with a reduced thickness (about $2 \mu \mathrm{m})$, compared to that observed for the wetting sample in Figure 9a (about $45 \mu \mathrm{m}$ ). This further confirms the idea that the formation of the interfacial layer takes place at the very early stages of the wetting process, and its thickness increases with time.
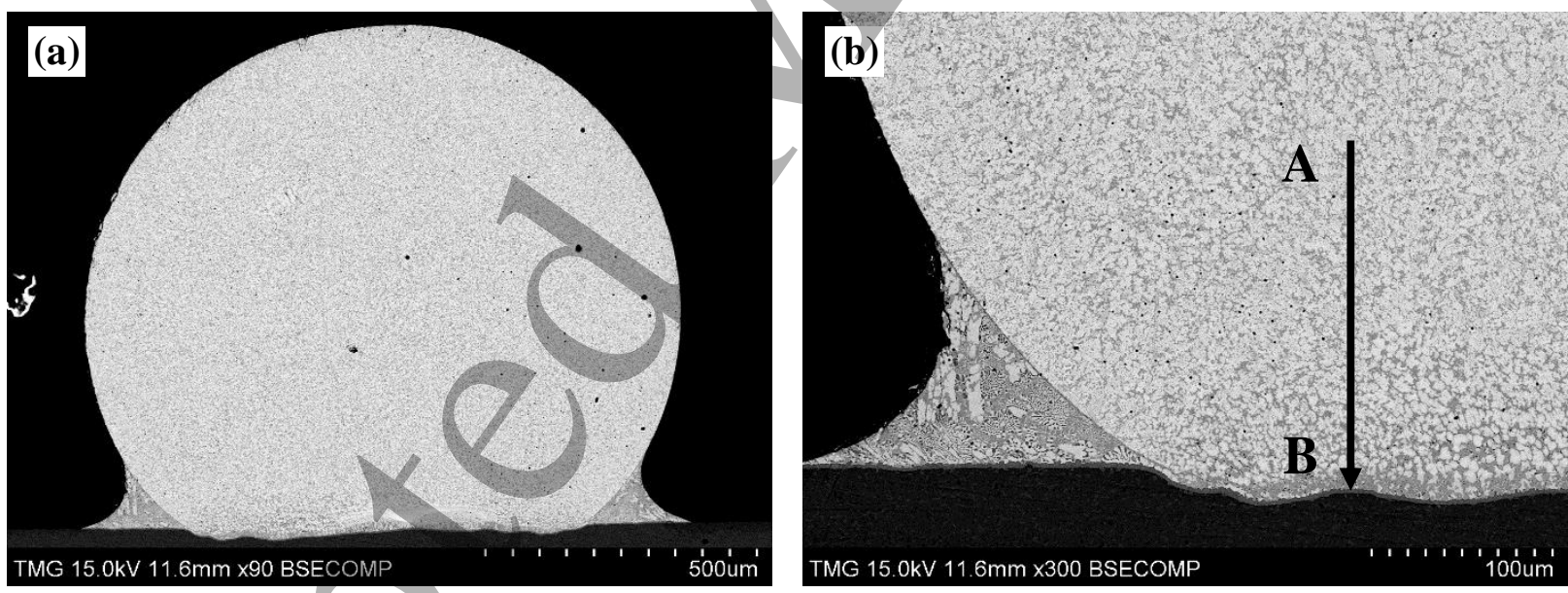

Figure 10. SEM back scattered image of (a) the sample cooled after $5 \mathrm{~s}$ and (b) the substrate/filler contacting region. Letters A and B indicate the direction of the line scan, corresponding to that in Figure 11 


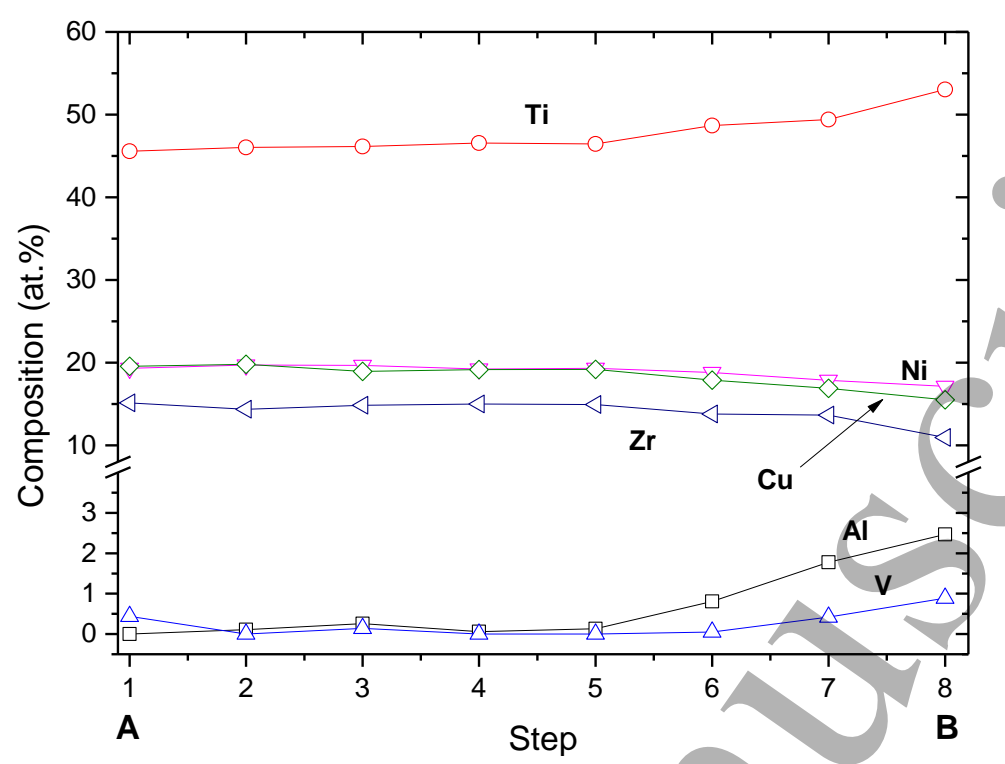

Figure 11. Line scan across the quenched sample. Letters $A$ and $B$ in the figure indicate the direction of the line scan, corresponding to that in Figure 10b

Another sample was cooled after $15 \mathrm{~s}$ from the melting onset, to ensure that the wetting/spreading is just at the end of the characteristic fast or "primary spreading" regime. This attempt was made to correlate the microstructural evolution of the interface of the samples to the observed wetting characteristics. At this stage, noticeable spreading ceases under this heating scheme. The back scattered electron images of this sample are shown in Figure 12. The dome or irregular shape of the surface of the droplet is due to the fact that the droplet was cooled before forming a full spherical cap. A critical look at Figure 12a indicates that a surface depression took place at the initial point of contact between liquid and solid, while the interface between the substrate and the filler remains fairly flat with minimal dissolution. This is a striking contrast to that obtained in Figure 9a, which corresponds to a furnace-cooled sample after $900 \mathrm{~s}$ of wetting test. This confirms the fact that this stage is governed by primary spreading regime, which takes place with very minimal dissolution of the substrate. This minimal dissolution of the substrate could be due to the fact that, at the very early wetting stage, most of the dissolved alloying elements (Ti, V and Al) are "restricted" to the interface, especially at the contact line region, due to the expected dominance of convective flow over diffusive flow. This might lead to a sort of transient saturation, in terms of the concentrations, of the dissolved alloying elements from the substrate, thereby drastically limiting further dissolution of the substrate. 

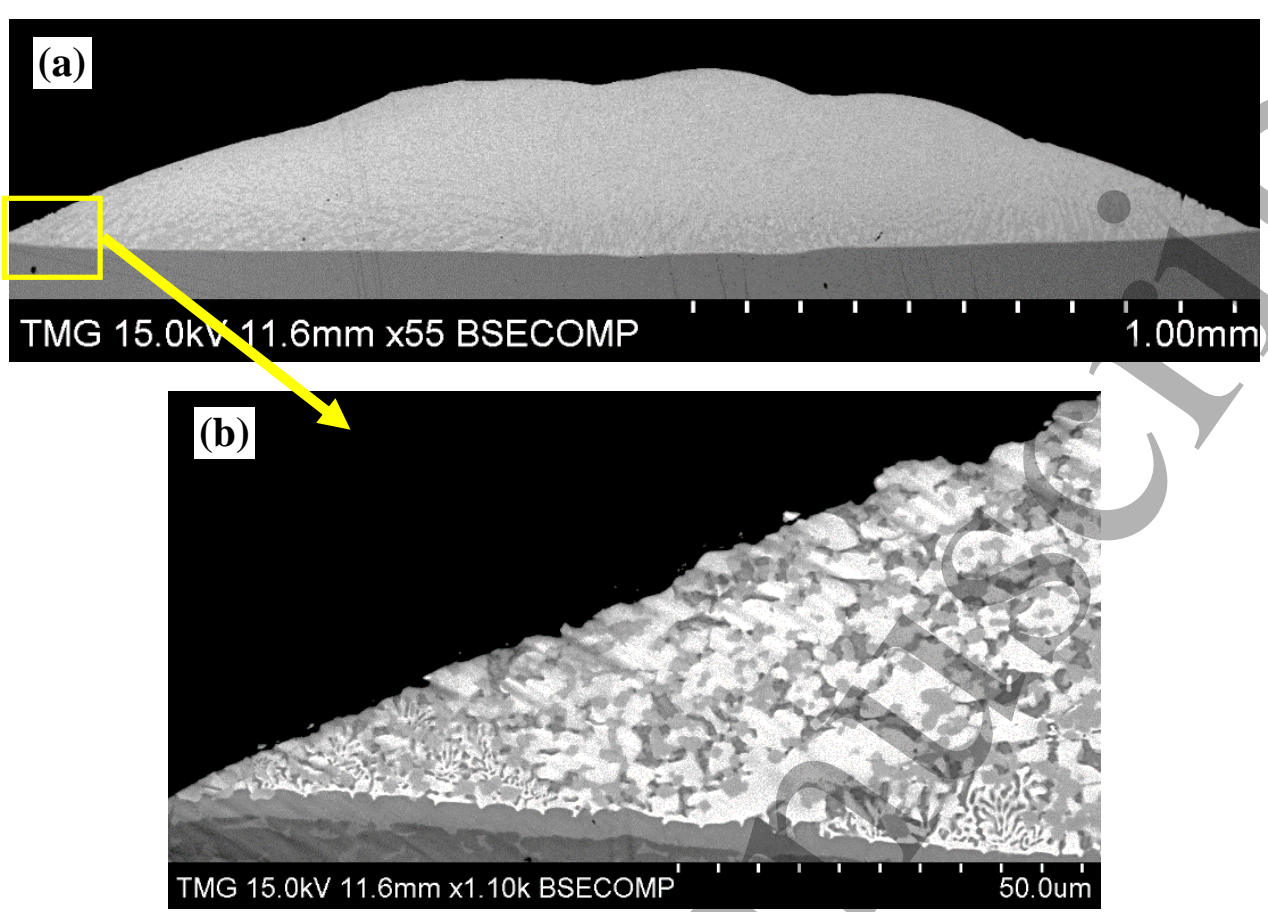

Figure 12. SEM back scattered images of (a) the sample cooled after $15 \mathrm{~s}$, (b) the substrate/filler contacting region

The interfacial layer could also be observed in Figure 12b, with an average thickness of around $2 \mu \mathrm{m}$, same as that of the sample cooled after $5 \mathrm{~s}$ (Figure 10). This layer is also expected to further limit the dissolution rate of the substrate.

It implies that if this brazing filler is used in industrial brazing of Ti-6Al-4V with the use of high heating rate, limited metallurgical reaction between the filler and the substrate can be achieved if the brazing time is kept as minimum as possible, thereby reducing the tendency for erosion of the substrate. Technically speaking, this fast spreading regime noticed under this scheme may not be described as being non-reactive due to the limited dissolution of the substrate and the formation of the thin interfacial layer. It is, however, representing a primary spreading regime. Therefore, what takes place after the end of the primary spreading regime is further dissolution of the substrate. At this later stage, diffusion becomes the dominant means of mass transport of atoms. The rate of diffusion of solute atoms from the interface into the drop bulk is expected to be faster than the rate of diffusion of solute atoms from the substrate into the interface. This implies that an increase in $\mathrm{Ti}, \mathrm{V}$ and $\mathrm{Al}$ concentrations change the chemistry of the liquid filler, which would have led to an increase or decrease in the extent of spreading. 


\subsubsection{Low heating rate}

The SEM back scattered electron images of the sample under low heating rate are shown in Figure 13a-c. For this sample, 3 distinct curvatures can be seen at the interface between the brazing filler and the substrate, represented by W, XY and YZ in Figure 13a.

The deep depression at the centre, marked $\mathrm{W}$, represents the initial point of contact between the brazing filler and droplet at the point of melting. This was followed by another curvature between points $\mathrm{X}$ and $\mathrm{Y}$. There is also a clear sign of dissolution of the substrate at this stage which is less than that at the central part (W). The dissolution depth decreases from $\mathrm{X}$ to $\mathrm{Y}$. The last distinct curvature is that between points $\mathrm{Y}$ and $\mathrm{Z}$. The surface of the substrate between these 2 points is flat, with the formation of the interfacial layer between the substrate and the filler. This last curvature, with its distinct characteristics, seems to correspond to the linear spreading stage identified on the contact angle-time graph (between points D and E of Figure 8b). Also, there seems to be formation of a eutectoid structure at the top and center of the filler, similar to that observed at the substrate/interface contacting line, as shown in Figure $13 \mathrm{~b}$ and c. This suggests that solidification at the triple point might have actually led to the arrest in the spreading. The presence of a coarse eutectoid in the middle portion if the droplet, shown in Figure 13c, suggests that the eutectoid is forming in different locations of the filler drop due to further decomposition of $\beta$-Ti when a slow heating rate is used for prolonged time.
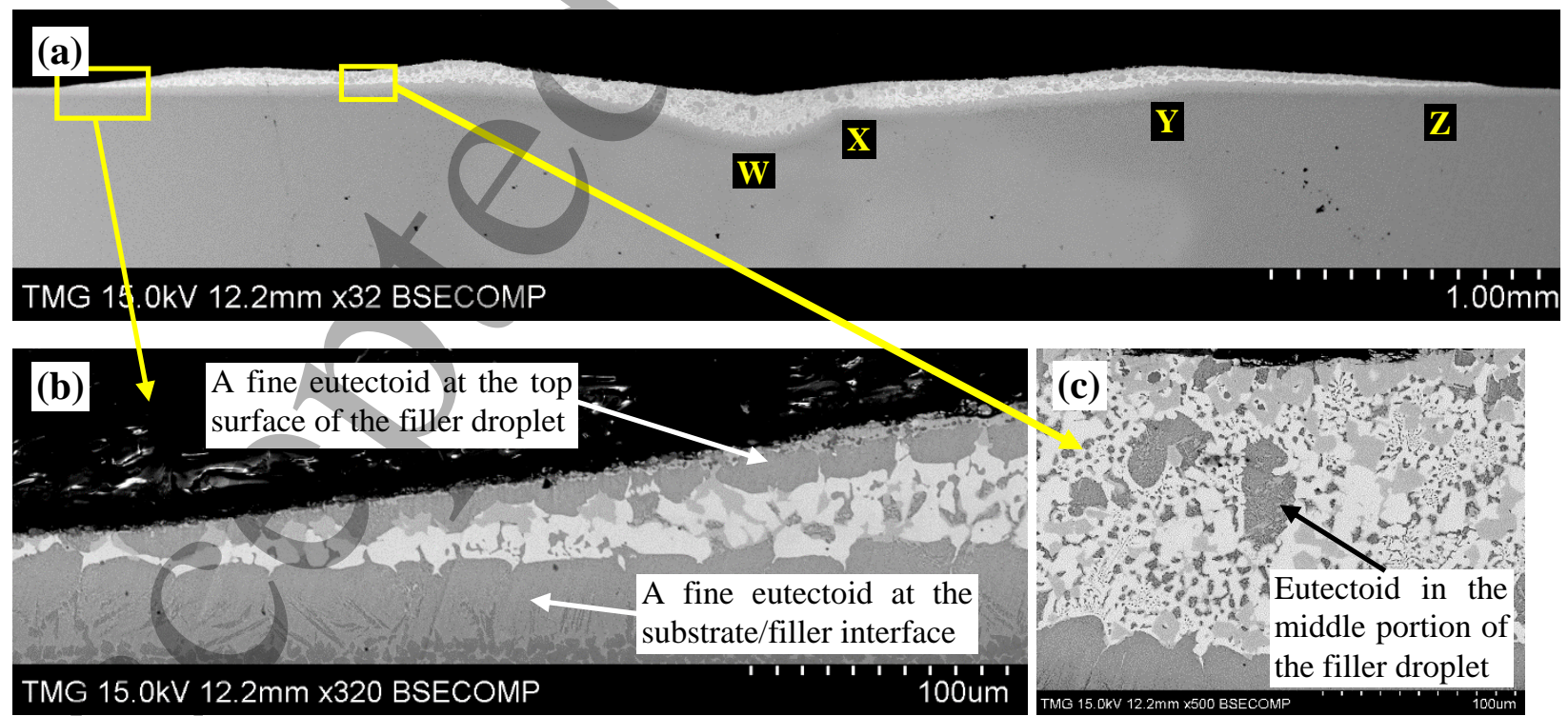

Figure 13. (a) SEM back scattered electron images of the wetting sample under low heating rate $\left(1.7^{\circ} \mathrm{C} / \mathrm{s}\right)$ scheme, (b) magnified portion showing top surface of the droplet at the contact line region and (c) magnified image focusing on the presence of fine eutectoid within the droplet components 
Figure 14 also shows the formation of a fine eutectoid ahead of the spreading brazing filler in the region marked $\mathrm{A}$. The result of the $\operatorname{EDS}$ spot $(1,2)$ analysis done at the edge of the droplet is shown in Table 5, which gives higher concentrations of $\mathrm{Al}$ and $\mathrm{V}$ as compared to those in Table 3. The spreading process, in this heating scheme, is associated with forming a layer of intermetallic compounds and with chemical adjustment of the filler melt. Protsenko et al. [49] suggested that wetting can be improved in systems in which intermetallic compounds are formed as a result of interfacial reactions, leading to the in-situ replacement of the oxidized surface by a clean surface of an intermetallic compound. There are other systems in the literature in which the formation of an interfacial compound ahead of the spreading droplet has been confirmed [38, 42, 44]. The extensive interfacial reaction between the brazing filler and the substrate and the associated driving force to further spread the filler might probably explain why the average value of the final apparent contact angle obtained under the low heating rate $\left(1.7^{\circ} \mathrm{C} / \mathrm{s}\right)$ scheme, $15^{\circ}$, is lower than the corresponding value, $37^{\circ}$, obtained under high heating rate scheme $\left(6.8^{\circ} \mathrm{C} / \mathrm{s}\right)$.

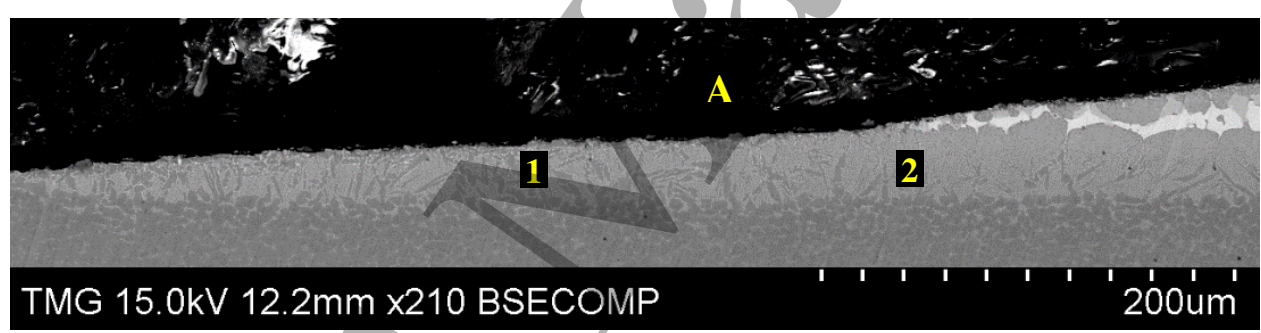

Figure 14. SEM back scattered electron image of the wetting sample under low heating rate $\left(1.7{ }^{\circ} \mathrm{C} / \mathrm{s}\right)$ scheme, showing the formation of the interfacial layer ahead of the droplet.

Table 5. EDS analysis of the edge of the wetting sample under low heating rate $\left(1.7^{\circ} \mathrm{C} / \mathrm{s}\right)$ scheme in atomic $\%$.

\begin{tabular}{|l|l|l|l|l|l|l|}
\hline Point & $\mathrm{Al}$ & $\mathrm{Ti}$ & $\mathrm{V}$ & $\mathrm{Ni}$ & $\mathrm{Cu}$ & $\mathrm{Zr}$ \\
\hline 1 & 7.57 & 72.16 & 4.13 & 3.71 & 7.88 & 4.56 \\
\hline 2 & 8.00 & 71.41 & 4.00 & 4.91 & 6.92 & 4.77 \\
\hline
\end{tabular}

The practical implication of using low heating rate in brazing of Ti-6Al-4V with Ti-20Zr- $20 \mathrm{Cu}-$ $20 \mathrm{Ni}$ brazing filler, based on the above results, is that there will be good wetting of the substrate by the filler. However, there will be intense metallurgical reaction between the substrate and the brazing filler, which might lead to erosion of the substrate. Also, longer time will be required to achieve successful brazing, compared to brazing using high heating rate.

\subsection{Effect of surface roughness on wetting}

In order to evaluate the effect of surface roughness of the substrate on the degree of wetting in this system, wetting experiments were done on both rough and smooth substrates, under each of the 
aforementioned heating schemes. The results of these wetting experiments are shown in Figures 15-17. From theses graphs, it can be seen that the degree of wetting is essentially the same for both rough and smooth substrates, under high heating rate and high heating rate with intermediate soaking schemes. However, considerable shift between the effects of roughness values on the wetting behavior could be seen in Figure 16. The smooth surface shows a uniform spreading with time, while the rough surface shows a sort of resistance-to-wetting prior the occurrence of primary spreading stage and a subsequent linear spreading stage. Due to the nature of the wetting experiments, the liquid phase of the filler material forms gradually upon heating until the liquidus temperature is reached, where a sudden melting occurs. For the smooth sample, the substrate was uniformly wetted by any formed liquid by the filler and the spreading process was driven by both diffusion and convection mechanisms without any topographic obstacles. However, the resistanceto-wetting, in the rough sample, can be due to the high surface area and topography imposed when the sample was roughened. In this case, the low energy liquid has to wet larger area and thus the spreading process is expected to be delayed, making the brazing filler droplet to maintain that transient steady contact angle for a longer time. This delay gives rise to accumulate the liquid, until the liquidus temperature is achieved, and forms a liquid phase with high energy. The high energy liquid, then, breaks the geometrical barriers and primary spreading takes place in a very short time. Hence, it can be concluded that the effect of surface roughness of the substrate on the degree of wetting in Ti-6Al-4V/Ti-20Zr-20Cu-20Ni system, in the range of the surface roughness values examined, is significant during the low heating rate scheme. However, the surface roughness effect on the degree of wetting in the Ti-6Al-4V/Ti-20Zr-20Cu-20Ni system is negligible. Effect of surface roughness on contact angle hysteresis, especially in non-reactive systems is documented in the literature $[50,51]$. 


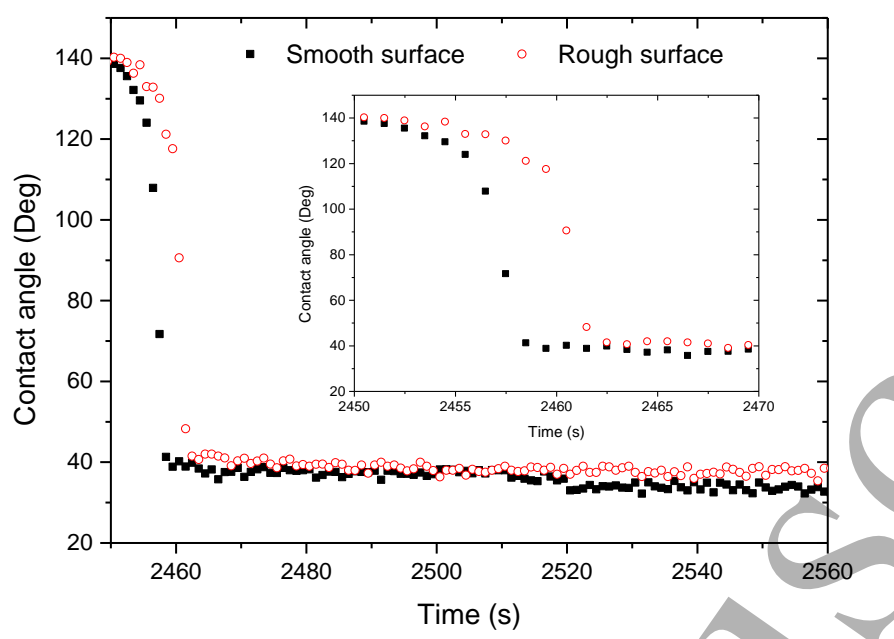

Figure15. Effect of surface roughness on wetting under the high heating rate $\left(6.5^{\circ} \mathrm{C} / \mathrm{s}\right)$ scheme. The inset shows the time span of 2450 to $2470 \mathrm{~s}$.

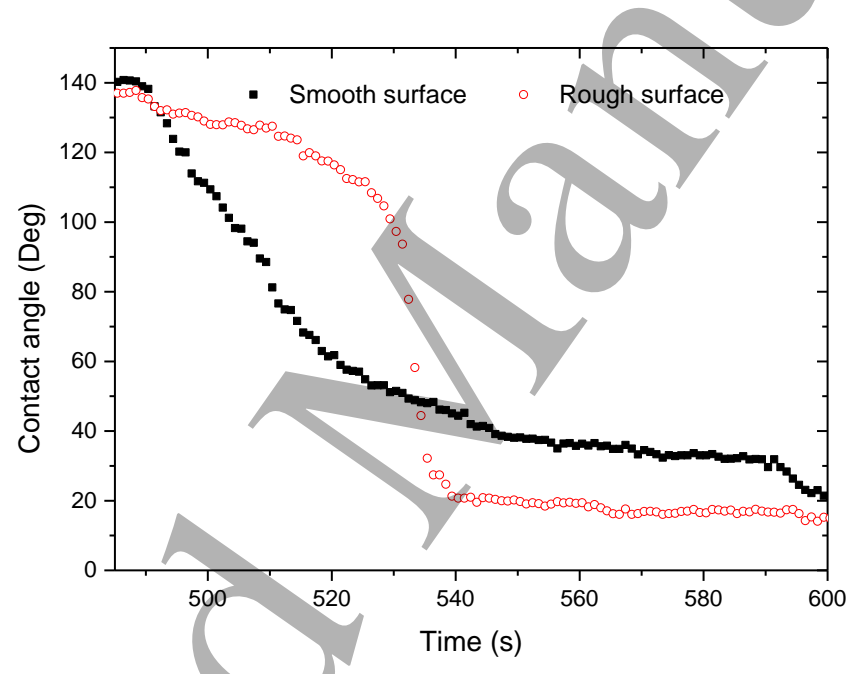

Figure 16. Effect of surface roughness on wetting under the low heating rate $\left(1.7^{\circ} \mathrm{C} / \mathrm{s}\right)$ scheme.

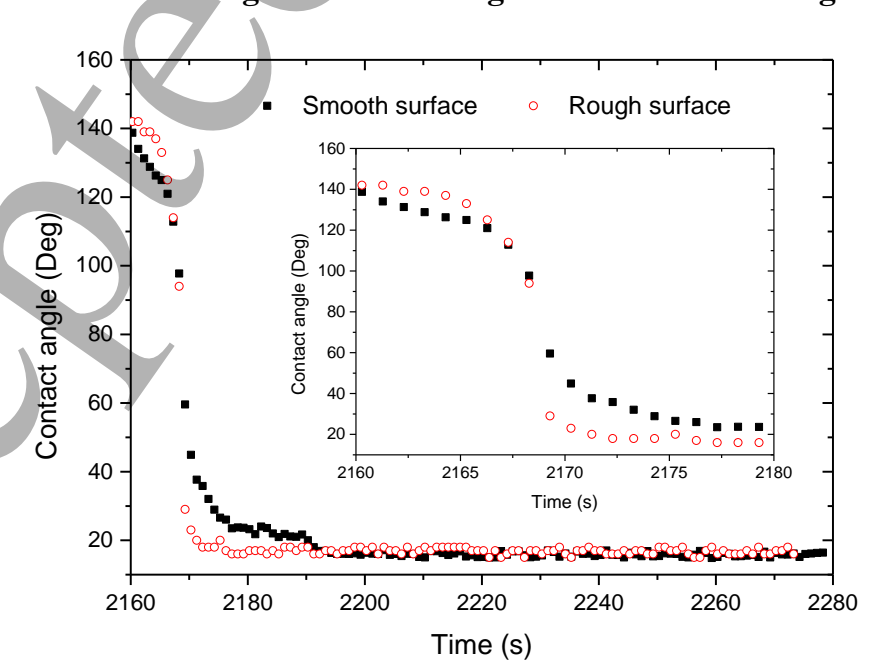

Figure 17. Effect of surface roughness on wetting under the high heating rate $\left(5.6{ }^{\circ} \mathrm{C} / \mathrm{s}\right)$ scheme with intermediate soaking at $650{ }^{\circ} \mathrm{C}$ for 5 minutes. The inset shows the time span of 2160 to $2180 \mathrm{~s}$. 


\section{Conclusion}

In this work, effects of heating scheme and the surface roughness of the substrate on the wetting of Ti-6Al-4V substrate by Ti-20Zr-20Cu-20Ni brazing filler have been studied. The nature of wetting in this system has been found to be reactive, it entails the dissolution of the substrate and the formation of interfacial reaction layer. The ability of the system to form the interfacial reaction layer has been found to have profound effect on the degree of wetting. Also, within the range of surface roughness values studied in this work, surface roughness of the substrate was found to have little or no effect on the degree of wetting of the substrate by the brazing filler when a high heating rate schemes were used. Whereas, the surface roughness influenced the degree of wetting significantly during the low heating rate scheme.

In wetting experiments involving a heating scheme with a high heating rate $\left(6.8^{\circ} \mathrm{C} / \mathrm{s}\right)$, a primary spreading stage has been identified. This stage is characterized with a high wetting/spreading rate with little dissolution of the substrate. In the use of heating scheme involving intermediate soaking at $650{ }^{\circ} \mathrm{C}$, the soaking process duration has been found to influence the wetting/spreading mechanism. When the soaking duration is less than 10 minutes, the wetting/spreading is found to be dominated by the primary spreading stage. However, for soaking duration lasting for 10 minutes and above, the wetting/spreading is dominated by the secondary spreading stage.

The heating scheme has been found to have profound influence on the degree of wetting of the substrate by the brazing filler. When the heating rate was high $\left(6.8^{\circ} \mathrm{C} / \mathrm{s}\right)$, the average value of the apparent contact angle of the filler on the substrate was $34^{\circ}$. When the high heating rate was supplemented with an intermediate soaking scheme at a temperature of $650{ }^{\circ} \mathrm{C}$, the average value of the apparent contact angle was found to be $18^{\circ}$. A very low heating rate $\left(1.7^{\circ} \mathrm{C} / \mathrm{s}\right)$ led to a measured apparent contact angle with an average value of $16^{\circ}$.

Based on the results of different heating schemes used in this work, brazing using high heating rate with intermediate soaking is recommended. With this heating scheme, Ti-20Zr-20Cu-20Ni brazing filler can wet Ti-6Al-4V substrate with final apparent contact angle as low as $18^{\circ}$, coupled with reduced dissolution or erosion of the substrate. Also, due to this soaking, thermal gradient is eliminated in the sample during temperature ramping.

\section{Acknowledgement}

Authors would like to acknowledge the help of Professor Mamoun Medraj in conceiving the work idea. The contribution of Mr. Rafid Khoja-Mendwi in designing the apparatus used for this study 
and the effort of Dr. Yasser towards a successful data collection are equally appreciated. Authors also wish to gratefully acknowledge the financial support from NSERC.

\section{References}

[1] P. J. Arrazola, A. Garay, L. M. Iriarte, M. Armendia, S. Marya, and F. Le Maître, "Machinability of titanium alloys (Ti6Al4V and Ti555.3)," J. Mater. Process. Technol., vol. 209, no. 5, pp. 2223-2230, Mar. 2009.

[2] H. Y. Chan and R. K. Shiue, "Study of brazing Ti-6Al-4V and TZM alloy using pure silver," J. Mater. Sci. Lett., vol. 22, no. 23, pp. 1659-1663, Dec. 2003.

[3] H. Izui and Y. Suezawa, "Study on Ti-6Al-4V alloy brazed with Ag-5Al-0.5 Mn filler metal," Weld. Int., vol. 3, no. 11, pp. 954-959, 1989.

[4] S. Y. Chang, L. C. Tsao, Y. H. Lei, S. M. Mao, and C. H. Huang, "Brazing of 6061 aluminum alloy/Ti-6Al-4V using Al-Si-Cu-Ge filler metals," J. Mater. Process. Technol., vol. 212, no. 1, pp. 8-14, Jan. 2012.

[5] R. R. Boyer, "An overview on the use of titanium in the aerospace industry," Mater. Sci. Eng. A, vol. 213, no. 1-2, pp.103-114, Aug. 1996.

[6] C. T. Chang, Y. C. Du, R. K. Shiue, and C. S. Chang, "Infrared brazing of high-strength titanium alloys by $\mathrm{Ti}-15 \mathrm{Cu}-15 \mathrm{Ni}$ and $\mathrm{Ti}-15 \mathrm{Cu}-25 \mathrm{Ni}$ filler foils," Mater. Sci. Eng. A, vol. 420, no. 1-2, pp. 155-164, Mar. 2006.

[7] C. T. Chang, Z. Y. Wu, R. K. Shiue, and C. S. Chang, "Infrared brazing Ti-6Al-4V and SP-700 alloys using the Ti-20Zr-20Cu-20Ni braze alloy," Mater. Lett., vol. 61, no. 3, pp. 842-845, Feb. 2007.

[8] A. E. Shapiro and Y.A. Flom, "Brazing of Titanium at Temperatures below $800^{\circ} \mathrm{C}$ : Review and Prospective Applications," Ohio, 2007.

[9] M. M. Schwartz, Brazing. Ohio: ASM International, Materials Park, Ohio., 1987.

[10] A. Shafiei, P. Abachi, K. Dehghani, and K. Pourazarang, "On the Formation of Intermetallics during the Furnace Brazing of Pure Titanium to 304 Stainless Steel Using Ag (30-50\%)-Cu Filler Metals," Mater. Manuf. Process., vol. 25, no. 11, pp. 1333-1340, Dec. 2010.

[11] V. H. López and A. R. Kennedy, "Flux-assisted wetting and spreading of Al on TiC.," J. Colloid Interface Sci., vol. 298, no. 1, pp. 356-62, Jun. 2006. 
[12] D. R. Milner, "A survey of the scientific principles related to wetting and spreading.," $B r$. Weld. J., vol. 5, pp. 90-105, 1958.

[13] C. A. Leon, V. H. Lopez, E. Bedolla, and R. A. L. Drew, "Wettability of TiC by commercial aluminum alloys,” J. Mater. Sci., vol. 37, no. 16, pp. 3509-3514, 2002.

[14] S. Amore, E. Ricci, G. Borzone, and R. Novakovic, "Wetting behaviour of lead-free Snbased alloys on $\mathrm{Cu}$ and Ni substrates," Mater. Sci. Eng. A, vol. 495, no. 1-2, pp. 108-112, Nov. 2008.

[15] T. D. Blake and K. J. Ruschak, “A maximum speed of wetting," Nature, vol. 282, no. 5738, pp. 489-491, 1979.

[16] D. Chatain and W. C. Carter, "Spreading of metallic drops.," Nature materials, vol. 3, no. 12. pp. 843-845, 2004.

[17] G. W. Liu, F. Valenza, M. L. Muolo, G. J. Qiao, and a. Passerone, "Wetting and interfacial behavior of Ni-Si alloy on different substrates,"J. Mater. Sci., vol. 44, no. 22, pp. 59905997, Sep. 2009.

[18] J.-G. Li, "Wetting of ceramic materials by liquid silicon, aluminium and metallic melts containing titanium and other reactive elements: A review," Ceram. Int., vol. 20, no. 6, pp. 391-412, Jan. 1994.

[19] J. C. Ambrose and M. G. Nicholas, "Wetting and spreading of nickel-phosphorus brazes : detailed real time observations of spreading on iron-chromium substrates," Mater. Sci. Technol., vol. 12, no. 1, pp. 72-80, 1996.

[20] D. Chatain, “Anisotropy of Wetting,” Annu. Rev. Mater. Res., vol. 38, no. 1, pp. 45-70, Aug. 2008.

[21] S. J. Hitchcock, N. T. Carroll, and M. G. Nicholas, "Some effects of substrate roughness on wettability," J. Mater. Sci., vol. 16, no. 3, pp. 714-732, 1981.

[22] B. Komolafe and M. Medraj, "Progress in Wettability Study of Reactive Systems," J. Metall., vol. 2014, pp. 1-14, 2014.

[23] C. C. Liu, C. L. Ou, and R. K. Shiue, "The microstructural observation and wettability study of brazing Ti-6Al-4V and 304 stainless steel using three braze alloys," J. Mater. Sci., vol. 37,pp. 2225-2235, 2002.

[24] H. Y. Chan, D. W. Liaw, and R. K. Shiue, "The microstructural observation of brazing Ti6Al-4V and TZM using the BAg-8 braze alloy," Int. J. Refract. Met. Hard Mater., vol. 22, no. 1, pp. 27-33, Jan. 2004. 
[25] R. K. Shiue, S. K. Wu, Y. T. Chen, and C. Y. Shiue, "Infrared brazing of Ti50A150 and Ti6Al-4V using two Ti-based filler metals," Intermetallics, vol. 16, no. 9, pp. 1083-1089, Sep. 2008.

[26] E. Ganjeh, H. Sarkhosh, M. E. Bajgholi, H. Khorsand, and M. Ghaffari, "Increasing Ti6Al-4V brazed joint strength equal to the base metal by Ti and $\mathrm{Zr}$ amorphous filler alloys," Mater. Charact., vol. 71, no. 15, pp. 31-40, Sep. 2012.

[27] C. T. Chang and R. K. Shiue, "Infrared brazing Ti-6Al-4V and Mo using the Ti-15Cu15Ni braze alloy," Int. J. Refract. Met. Hard Mater., vol. 23, no. 3, pp. 161-170, May 2005.

[28] T. Chung, J. Kim, J. Bang, B. Rhee, and D. Nam, "Microstructures of brazing zone between titanium alloy and stainless steel using various filler metals," Trans. Nonferrous Met. Soc. China, vol. 22, pp. 639-644, Dec. 2012.

[29] I.-T. Hong and C.-H. Koo, "Microstructural evolution and shear strength of brazing C103 and Ti-6Al-4V using Ti-20Cu-20Ni-20Zr (wt.\%) filler metal," Int. J. Refract. Met. Hard Mater., vol. 24, no. 3, pp. 247-252, May 2006.

[30] L. Liu, "Automated measurement of contact angles for sessile droplets using matlab image and analysis library." [Online]. Available: http://www.ecf.utoronto.ca/ liuwei12/resources/WardReport.pdf.

[31] L. Yin, B. T. Murray, S. Su, Y. Sun, Y. Efraim, H. Taitelbaum, and T. J. Singler, "Reactive wetting in metal-metal systems.,"J. Phys. Condens. Matter, vol. 21, no. 46, pp. 1-11, Nov. 2009.

[32] Alloy Phase Diagrams, vol.3. ASM International, 1992.

[33] K. P. Gupta, "The Cu-Ni-Zr System (Copper-Nickel-Zirconium)," J. Phase Equilibria, vol. 21, no. 6, pp. 553-561, 2000.

[34] R. Arroyave, T. W. Eagar, and L. Kaufman, "Thermodynamic assessment of the Cu-Ti-Zr system,” J. Alloys Compd., vol. 351, pp. 158-170, 2003.

[35] D.-M. Lee, J.-H. Sun, S.-Y. Shin, J.-C. Bae, and C.-H. Lee, "Improvement of Glass Forming Ability of Cu-Ni-Zr-Ti Alloys by Substitution of Hf and Nb," Mater. Trans., vol. 49, no. 6, pp. 1486-1489, 2008.

[36] P. Bhagawath, K. N. Prabhu, and Satyanarayan, "Wetting Behavior of Reactive and NonReactive Wetting of Liquids on Metallic Substrates," World Acad. Sci. Eng. Technol., vol. 73, pp. 978-981, 2013.

[37] L. Yin, B. T. Murray, and T. J. Singler, "Dissolutive wetting in the Bi-Sn system," Acta Mater., vol. 54, no. 13, pp. 3561-3574, Aug. 2006. 
[38] L. Yin, S. J. Meschter, and T. J. Singler, "Wetting in the Au-Sn System," Acta Mater., vol. 52, no. 10, pp. 2873-2888, Jun. 2004.

[39] L. Yin, A. Chauhan, and T. J. Singler, "Reactive wetting in metal $/$ metal systems: Dissolutive versus compound-forming systems," Mater. Sci. Eng. A, vol. 495, no. 1-2, pp. 80-89, Nov. 2008.

[40] J. G. Lee, G. H. Kim, M. K. Lee, and C. K. Rhee, "Intermetallic formation in a Ti-Cu dissimilar joint brazed using a Zr-based amorphous alloy filler," Intermetallics, vol. 18, no. 4, pp. 529-535, Apr. 2010.

[41] O. Dezellus, F. Hodaj, C. Rado, J. N. Barbier, and N. Eustathopoulos, "Spreading of Cu-Si alloys on oxidized $\mathrm{SiC}$ in vacuum: Experimental results and modelling," Acta Mater., vol. 50, pp. 979-991, 2002.

[42] K. Landry and N. Eustathopoulos, "Dynamics of Wetting in Reactive Metal/Ceramic Systems : Linear Spreading,” Acta Mater., vol. 44, no. 10, pp. 3923-3932, 1996.

[43] N. Eustathopoulos, "Progress in understanding and modeling reactive wetting of metals on ceramics," Curr. Opin. Solid State Mater. Sci., vol. 9, no. 4-5, pp. 152-160, Aug. 2005.

[44] O. Dezellus, F. Hodaj, and N. Eustathopoulos, "Chemical reaction-limited spreading: The triple line velocity versus contact angle relation," Acta Mater., vol. 50, pp. 4741-4753, 2002.

[45] O. Dezellus, F. Hodaj, and N. Eustathopoulos, "Progress in modelling of chemical-reaction limited wetting," J. Eur. Ceram. Soc., vol. 23, no. 15, pp. 2797-2803, Jan. 2003.

[46] O. Dezellus and N. Eustathopoulos, "Fundamental issues of reactive wetting by liquid metals," J. Mater. Sci., vol. 45, no. 16, pp. 4256-4264, Jan. 2010.

[47] J. A. Warren, W. J. Boettinger, and A. R. Roosen, "Modeling reactive wetting," Acta Mater., vol. 46, no. 9, pp. 3247-3264, 1998.

[48] J. J. Stephens and S. K. Weil, Eds., "Brazing and Soldering. Proceedings of the 3rd International Brazing and Soldering Conference.," 2006, pp. 1-413.

[49] P. Protsenko, A. Terlain, V. Traskine, and N. Eustathopoulos, "The role of intermetallics in wetting in metallic systems," Scr. Mater., vol. 45, no. 12, pp. 1439-1445, Dec. 2001.

[50] S. G. Kandlikar and M. E. Steinke, "Contact angles and interface behavior during rapid evaporation of liquid on a heated surface," Int. J. Heat Mass Transf., vol. 45, no. 18, pp. 3771-3780, Aug. 2002. 
[51] B. He, J. Lee, and N. A. Patankar, "Contact angle hysteresis on rough hydrophobic surfaces," Colloids Surfaces A Physicochem. Eng. Asp., vol. 248, no. 1-3, pp. 101-104, Nov. 2004. 